\title{
Effects of Turkish Dramas on University Students: A Survey of Pakistani Universities
}

\section{Mehwish lqbal*}

Department of Mass Communication and Media Studies, University of Gujrat, Gujrat, Pakistan

\begin{abstract}
The aim of this study is to investigate the "Effects of Turkish dramas on University students". Drama plays an important role in the personality building of viewers. Because through the drama persons are changing their living styles, dressing styles and also comes to know about the values and norms of other nations. In this study researcher want to know the Turkish drama effects on young generation of Pakistan. And all know that University students are the young generation of Pakistan. In this present study survey research method was chosen and three Universities of Pakistan were chosen for this research purpose, which are "University of Gujrat, Gujrat", Arid Agriculture University Rawalpindi and Punjab University Lahore. Quantitative research method was selected. Nonprobability sampling method was selected and in non-probability sampling random sample were used as a technique of data collection. Questionnaire is use as a tool of data collection and 300 samples size were selected. In this research three hypotheses were develop i.e., 1. University students are influenced by the styles of models of Turkish dramas. 2. University students are trying to adopt their styles. 3. Turkish dramas are affects Islamic values among University students. Findings of this research show that first two hypotheses were accepted and third hypothesis was rejected. University students are affected by Turkish dramas but do not affect Islamic values among University students.
\end{abstract}

Keywords: Turkish dramas; University students; Adaptation; Celebrities style

\section{Introduction}

Turkish dramas dubbed in Urdu to entertain the audience. This is an obviously low cost business strategy adopted by our channels. Our local artists and directors have raised their voice against the airing of foreign content on our TV channels and this is a much needed-step [1]. However, no considerable objection has been raised on the declining quality of our own productions. And yet, Juggan Kazim's open in The Express Tribune brought a flicker of hope amidst this declining trend in the entertainment industry. Her effort is quite commendable as she categorically states her opinion on the matter:

"There is the decaying drama industry that seems to focus mostly on the affairs of married people. The stories are awful and the production values are worse. There is little regard for character development" [2].

Turkish dubbed soap operas in changing the life styles of female youth. The main aim of this study is to understand that to what extent these dramas are being watched by females and to what amount these dramas are affecting the interpersonal communication, dressing and talking styles of the young females [3].

Gone are the days when families would sit together and watch Pakistani dramas. Instead, today we get to see the 'not-so-moving' storylines that seem to be inspired by Indian soaps. What is worse is that our TV channels show things that are in direct contradiction with our cultural and social values.

\section{After India, Turkey to launch a Pakistani drama based channel}

It wasn't long when Pakistani dramas became super hit among Indian grassroots. Now the industry is all ready to charm Turkish audience with a recently launched Turkish channel that will focus on airing Pakistani drama content only. The channel will also have a morning show named 'Sunrise from Istanbul', hosted by commended actress, Maria Wasti. The morning show will be a joint venture between Pakistan and Turkey [4]. Pakistani stars were spotted enjoying their stay and shoot in Istanbul. Stars like Anoushey Ashraf, Humayun Saeed, Hamza Ali Abbasi, Nouman Ejaz, Sanam Saeed, Fahad Qureshi, Mohib Mirza, Amna Ilyas, among other Pakistani celebrities are having a truly good time in Istanbul.

Now Turkish dramas are playing by different TV channels. These dramas are threats to our Urdu dramas and especially to our Pakistani culture. These dramas are against to our customs, tradition and culture. Turkish dramas are promoting vulgarity in our society. These dub dramas are destroy our Pakistani Urdu dramas. Pakistani Urdu dramas are not portrayed true picture of women.

From pregnancies to abortions, from extra-marital affairs to illegitimate children and elopements, we have been exposed to all kinds and degrees of absurd content in these dramas in the name of modern entertainment. Even respectable relationships are not spared. I have seen countless dramas where a guy falls in love with his niece or his daughter's friend or a girl starts having an affair with her brotherin-law, and uses all sorts of ploys and unfair means to make him her life-partner [5]. These dramas even show maids being used as objects of physical pleasure and satisfaction by their male employers.

\section{Junoon Tere pyar ka Turkish drama serial by hum TV}

Junoon tere pyar ka is a Turkish drama which is dubbed in Urdu. It is transmission on hum TV. Turkish dramas are very famous in Pakistan TV channels in these days and particularly their love stories

*Corresponding author: Mehwish lqbal, Department of Mass Communication and Media Studies, University of Gujrat, Gujrat, Pakistan, Tel: +92 53 3643112; E-mail: mehwish_iqbal34@yahoo.com

Received August 31, 2018; Accepted October 08, 2018; Published October 15, 2018

Citation: Iqbal M (2018) Effects of Turkish Dramas on University Students: A Survey of Pakistani Universities. J Mass Communicat Journalism 8: 394. doi: 10.4172/2165-7912.1000394

Copyright: (c) 2018 lqbal M. This is an open-access article distributed under the terms of the Creative Commons Attribution License, which permits unrestricted use, distribution, and reproduction in any medium, provided the original author and source are credited. 
are very exciting and are liked by people of Pakistan. After TV channel Urdu 1, Geo TV, Geo Kahani channels now Hum TV also launched a Turkish love story serial 'Junoon Terry Pyar Ka'. Urdu 1, Geo TV, Geo Kahani TV channels presents many Turkish dramas to Pakistani people while hum TV is going to introduce Turkish drama first time on a TV channel (www.web.pk)

In Turkish language the name of this drama is Lale Devri which means Tulip while here in Pakistan its name is janoon tery pyar ka. People are like to see the Turkish drama but there is negative response also. When Turkish drama first time started on Pakistani channels many actors and producer doesn't want to launch dramas on other countries but people like to see these dramas and that is why many Turkish dramas are seeing this year on different TV channels.

These are only a few examples of all the absurdities that we are being interested with in the form of dramas like Mera Saaein, Maat, Kitni Girhen Baqi Hain, Tair-e-Lahoti, Mujko Khuda Pe Yaqeen Hai, Maane $\mathrm{Na}$ Yeh Dil - the list can go on and on. One entertainment channel even went to the extent of viewing an apparently unmarried couple living under the same roof as husband and wife in Rishtay Kuchh Adhooray Se [6].

By following in the footsteps of international media, we are intentionally or unintentionally destroying our own culture and consequently, losing our identity. This obsession with competing with something that does not represent us as far as our social values and culture is concerned needs to be addressed on an urgent basis because it has a direct influence on the mindset of our younger generation. The media industry must realize the impact such things can have on our society. All those associated with this industry have a huge responsibility on their shoulders to mend their ways for a better society (blogs.tribune.com.pk)

\section{Turkish dramas on Pakistani Channels}

Noor (Turkish Drama) on Geo Entertainment

Ishq-e-Mumnuh (Turkish) on Urdu1 TV Channel

And so on........ (www.wiredpakistan.com).

\section{Variables}

A variable is an object, event, idea, feeling, time period, or any other type of category you are trying to measure. There are two types of variables-independent and dependent. There are two variables in this study first the Turkish dramas and second is University students.

\section{Independent variable}

It is a variable that stands alone and isn't changed by the other variables you are trying to measure. For example, someone's age might be an independent variable. In this study independent variable is "Turkish dramas".

\section{Dependent variable}

It is something that depends on other factors. For example, a test score could be a dependent variable because it could change depending on several factors such as how much you studied, how much sleep you got the night before you took the test. And dependent variable in this study is "Turkish drama models styles, adopt styles of Turkish dramas models among University students and Islamic values".

\section{Significance of study}

As we know that Turkey is known as Islamic country and that is close to our religion. Due to this the influence of Turkish dramas are more in our society especially on females and young generation like University students. In this research the researcher want to know that how Turkish dramas are influence to changing the life style of University students' especially female students according to the models presented by Turkish dramas.

And also want to know that the Turkish religion is close to Pakistani religion then due to Turkish dramas what are the effects of these dramas which are presented by our local channels on our University students.

\section{Objectives of study}

1. To find out that the University students are influence by the dressing styles of models of Turkish dramas

2. To identify that the University students are adopt the styles of Turkish dramas models.

3. To find out that Turkish dramas are affect the Islamic values among University students.

\section{Research question}

Q1. Is that Turkish dramas are affecting the Islamic values among University students?

Q2. How university students are influence by the dressing styles of models of Turkish dramas?:

Q3. What do you think University students are adopting the styles of Turkish dramas models style?:

\section{Hypothesis}

1. Turkish dramas are affecting Islamic values among University students.

2. University students are influenced by the styles of models of Turkish dramas.

3. University students are trying to adopt their styles.

\section{Literature Review}

Shabir et al. [7] conducted a research on "Cultural effects of Urdu dramas of Geo and Hum TV on women: A case study of Bahawalpur, Pakistan". The researchers also analyze that these TV channels are promoting Pakistani culture or not. The study also indicates that the $\mathrm{w}$ omen of Bahawalpur City adopted the styles of models that are shown in Geo and Hum TV channels. Baran says that media is saturating our everyday lives that we are often unconscious of their presence, not to reveal their influence. Media inform us, entertain us, enjoyed us, and annoys us. Media moves our emotions, challenges our mind, and insults our intelligence." Findings show that these channels are promoting Pakistani culture among society. And also these dramas are changing the religious and social setup of Pakistani society. Geo Kahani is the source of promotion of Turkish dramas in Pakistani entertainment channels. Dramas are the main source to adopt or nonadopting the things those are presenting in the TV dramas. Some Urdu dramas show sister revival sister which is totally against our moral and cultural values. Mostly girls or women are wearing western clothes. Most of these dramas are presenting the women issues which are facing in society by women faces in the society. Zaid bin Ismail, Rao conducted research on "impact of Television on youth". He found that "Due to television programs the views of student of Punjab University had modernized. Their views about different issues have modernized like parental authorities, women's freedom, coeducation etc. 
Shahbaz Aslam et al. [8] conducted a research on "Socio-Ethical Impact of Turkish Dramas on Educated Females of GujranwalaPakistan". Turkish culture is close to our Pakistani culture and Turkish dramas are directly influence the Pakistani culture and society. In this study 100 sample size is selected randomly through survey research. This study shows Turkish dramas are the best source of entertainment and good source of time pass. The analysis of our research shows that despite of perception of Turkish dramas and possible threat yet there is a struggle against such odds that harm and also reshape our socio-ethical values. The study will describe how females perceives about social and ethical concepts from Turkish dramas about family relations, marriage, divorce, etc and how these concepts are being reformed under the influence of western thoughts. And also the study will be focused that whether Turkish culture being an Islamic country raise our cultural diversity or resulted in clash of culture and will damage of social stuff. Zia [9] in her PhD. thesis titled "Impact of Cable Television on Women" concluded that women viewers of cable television tend to show a greater degree of acceptance of television characters" appearance and style than males.

Ghazanfar et al. [10] conducted a research on "Cultural institutions under the influence of information communication technologies". "Information and communication technologies (ICTs) are broadly defined as technologies used to convey, manipulate and store data by electronic means". Media is the best source of communication system and dramas are the source which is exchange cultural and societal impacts on one another societies. They use both qualitative and quantitative sampling tools and collected data in six weeks from 50 respondents. Now days there are different countries contents played in Pakistani news channels. And mostly Indian and Turkish dramas played by Pakistani channels. Turkish culture is close to Pakistani culture and religion and it to Islam religion due to their drama industry. Due to the changing the time period lifestyle of the current generation has clearly changed. The food patterns, clothing trends, pastimes etc have all changed. Television the most powerful communication technology that is used as a tool to promote views, predefined images, cultures and beliefs. "Islamic films are presenting by broadcasting media especially in Malaysia, Turkey, Indonesia and Iran to serve Muslims".

Madni et al. [11] conducted a research on "Portrayal of fashion by Turkish and Pakistani dramas on private channels and viewers' perception". TV is the major source of communication between every nation. Due to Television we know the culture, values and living style other countries. We share our culture and societal values and life style of different nations and also adopt the life style of western nations according to our choice. In this research 300 sample size selected researcher collected data from 300 respondents with the help of stratified sampling and for this purpose use survey research method. The data collected from the female students of Sargodha University, working women and housewives of Sargodha city. And for this purpose researcher select two Television entertainment channels Hum TV and Urdu 1. The findings of this research show that females like shalwar kameez suits rather than miniskirts which are presented the dressing style of females in Turkish dramas. Globalization of media coverage of the national public broadcaster it is more important national and local cultural, educational, and public affairs programming is to provide programming. Today, more drama is viewed every week or on every weekend, and then watched in a year or even in a lifetime in the historical period.

Dubow et al. [12] wrote a book and in chapter $6^{\text {th }}$ of this book is about "Media and youth socialization (underlying processes and moderators of effects)". Today's youth are exposed to a "media saturated environment", which has long been a concern of parents, educators, policy makers, professional groups, and researchers and there is much empirical evidence of meaningful effects of media exposure on youth. Now a day's youth spend more time watching television and adopt the life style and dressing patterns according to their favorite celebrity's life style. In these days Turkish dramas are on top by which people watch because these Turkish dramas are more presented in Pakistani media. The overarching principle to describe what happens has been called the replacement of functionally similar activities. These dramas have long term effects on youth. Mass media is in fact a key socializing influence in every child life. Many have investigated what activities diminish when children devote more and more time on mass media.

Madni et al. [11] conducted a research on "Gender interaction pattern on private television channels' Turkish \& Pakistani dramas and viewer's perception". Entertainment industry plays a major role in transferring culture and traditions. Some people criticize dramas because dramas sometimes cross the limits and present immoral things. In this study researchers want to know about the watching habits of female viewers of Sargodha city and also want to explore female viewer's perception regarding Turkish and Pakistani dramas of private television channels. For this research the researchers choose respondents from female students, working women and housewives of Sargodha city. Stratified sampling was adopted for this study and to population was divided into different strata for example students, working women and housewives and then sample size of 300 was chosen by using the purposive technique of sampling. Television provides a platform to raise questions and share point of view, it also created problems. During the prime time almost every type of people with different age group geographical area, culture and education level watches television. The findings show that most of the respondents watch Hum TV rather other channels. Results shows that Turkish dramas present more mix gathering, joint office work, drinking habits in parties, dancing, hand shaking, kissing, and modeling then Pakistani dramas.

Zia [9] wrote thesis on "Effects of cable television on women in Pakistan: A comparative study of heavy and light viewers in Lahore". In this study researcher want to investigate the "effects of cable television on the life patterns of women in Lahore". The sample size is 432 women aged 18-40 years and watching cable television for a minimum two years. Greater the exposure to cable television greater the impact on the lives of women is the main hypothesis of this research. The results of this research presented by in two categories like general findings and major findings. In general findings most of the respondents were aged in 31 to 40 years. They all are graduates but unemployed and also belongs both upper and middle classes. In Lahore there is cable television is the main source of entertainment and in this study respondents complained that men have more rights to watch cable television then women. To test the hypothesis "greater the exposure to cable television greater the effect on the lives of women" use chi square statistical test. It is proved that those women who watch television more affected their activities like newspaper reading, going to cinema, the meals cooking and serving schedule, their domestic or personal expenditure and interaction with friends or and relatives. They were likely to accepting the role, culture and lifestyle of western and Indian women watched on cable channels.

Bicer [13] conducted a research on "The important of TV on the religious understanding of Turkish people”. In this research researcher examine that television programs are informative and how they change point of view of people about religion. In television that media is to 
educate the people. There is a major role of changing the life style of adult people and their understanding about religion. Researcher also deal with the position of media in modern Turkey especially about adult education, he said we will look into television programs from a socio-cultural and educational perspective. It should be taken into consideration the fact that mass media has some prejudices on religion. The modern religious education argues that the former religious teaching did not combined new developments both in educational sciences and in the religious understanding of the Turkish society. In Turkey daily relations, Turkish youth refer to discourses and communicative instruments of Western societies. This, in a sense, is also an impact of the rapidly globalizing world. Whereas television is on the top of the list as the major instrument of influence of the globalizing world among the masses, Internet has a secondary place, mostly common among the younger sections of the Turkish society. According to this point of view, Turkish Muslim society has a religious understanding, which is distinct from the Arabic Islam. The main axis of Turkish Islam revolves around a discourse, which stresses staying away from formalism, not resembling in its dressing codes to Arabs, and more freedom for women.

Cetin [14] conducted a research on "The Politicization of Turkish television dramas". States that the flow of television restored national memory and identity in Japan during the 1960s by defining morning, noontime and evening time spaces in which national memories were related to the national history through soap operas and dramas in specific. This article is based on the revolution of dramas on Turkey. The politicization of dramas has several dimensions of connection between politics and television, in which particular links can be identified. First nation states are well broken the national identities with their defining ideal citizenships or activating national views such as India (Mankekar, 1999; Rajagopal, 2001), Egypt (Abu-Lughod, 2005), China (Rofel, 2002), Brazil (Porto, 2011; Tufte, 2000), and so on. The role played by public broadcasting in constructing national identities may be looked ordinary. On the other hand, the entangled interests of governments and private broadcasting companies cover the way for redefining the nation's boundaries via television shows. Second, the nexus can be highlighted in television dramas depicting social issues. Syrian dramas offer certain social and political paintings framed by "the demise of communism, the perceived failures of nationalism, and the rise of Islam. Dramas Arabic, "Musalsal" commonly raised social issues such as corruption, role of religion and excess in society or the status of women, sometimes things too strong.

Khan et al. [15] conducted a research on "Impact of mass media in Pakistan on social, ethical and economic grounds". Mass media is playing tri-dimensional role in Pakistani society to inform, educate and entertain the people with the positive and negative effects. A comprehensive questionnaire is used for collecting the data from the respondents. Non probability sampling method was used in this study in which convenience sampling technique was adopted. For this research purpose 200 respondents were selected from the different cities of Pakistan for the data collection. In this study the results if this study indicates that there is no association between age groups, source of mass media entertainment, frequently accessed media content and views of people regarding the impact of media on society and ethics. According to oxford dictionary the action of providing or being provided with amusement or enjoyment is entertainment. Now a day in this busy routine life where a lot of burden on the shoulders of everyone there is some need of entertainment and enjoyment that everyone can release their burden from their shoulders is getting from television. Print media, television, radio, internet are the best source of entertainment. These days where everyone having a lot of work and tension there dramas, films are the best thing which helps people to entertain and enjoyed for some time in their busy life style.

Abbasi et al. [16] conducted a research on "Ethical issues in advertising in Pakistan: An Islamic perspective". In this article, the researchers want to investigate the ethics involved in advertising campaigns in Pakistan, in conflict with Islamic Sharia. For days now what kind of dramas and plays advertised on television is totally against Islamic values. Embarrassing attitudes of the public, which is displayed, read and hear about the ad campaigns that nudity and sexual images to the public and private portray negative messages appear when people see this type of content in a setting with a family gathering. Now days when people setting in the family gathering and such kind of shows onair on television then everyone feel embracement from their relatives and family. Cultural norms and values of society play an important role in shaping the attitudes of its people. And the TV shows. Dramas and films are destroying the Islamic values, norms. Because other nations shows are mostly seeing and promoting in private TV channels. Organizations that are making use of indecent language, nudity in advertisements for marketing their products in Pakistan are creating offensiveness in the minds of consumers for their products.

Rousselin [17] conducted a research on "Turkish soap power: International perspectives and Domestic Paradoxes". In which 2005 turkey telecasted ATV drama which was clearly a portrayal of western culture. Due to its successful and famous viewership this drama was later dubbed and re-telecasted in whole Arab. Instead of high criticism this drama gain gathered 85 million viewers throughout the Arab world. This drama became a first step for turkey because after this drama a lot off dramas were telecasted to enhance showbiz industry as well as portrayed soft picture of turkey outside the world. Three most successful Turkish TV dramas of all time are: A Thousand and One Nights Tells the story of a reputed architect's only son suffering from a decease who could only be saved by a transplants son suffering from a decease who could only be saved by a transplants as well as and downs of his love story. Forbidden Love depicts wealthy widower guy Adnan's taboo love story and magnificent Century life of the tenth Sultan Suleiman of Turkey. These dramas along with many other Turkish dramas got successful instead of criticism Contemporary Turkish series present an image of stability wherein contemporary practices and Western lifestyles can exist all together with Islamic and Arab identities and culture. There is a bit balance between the different traditions and actions of today's world and which has both an Eastern and Western appeal which also look attractive. Now Turkish screenwriters have learned to adapt these shows to local themes with Muslim storylines in order to gain more cultural interest. Ya-banci Dama "The Foreign Groom" was firstly telecasted in Greece under the name "The Borders of Love". With subtitles, "The Borders of Love" was an attractive love story of a poor boy of Turkish baklava-makers and a rich girl of a of a Greek business man. Turkish dramas depict cultural themes and cultural religion taboos such as daily life of an unmarried couples pre-marital affairs, complex sexuality "Forbidden Love"; nonstandard family models and moral dilemmas ("A Thousand and One Nights"); high alcohol consumption and private life of some major historic tycoons ("Magnificent Century"); abortion was extensively discussed in "Noor"; drinking, swearing and smoking. Women's independence as depicted in Turkish dramas could gradually extend gender relationships in Arab societies. Impact of Turkish dramas cannot be negated because of dense TV hours and high viewership. Turkish government is taking television industry as its foreign policy setter, outside face of turkey to the world, culture mixture as well as 
tourism opportunity. A time will come when culture of turkey and Europe will be mixed as long that a common man wouldn't be able to differentiate between these two.

Cerami [18] conducted a research on "Rethinking Turkey's soft power in the Arab world: Islam, Secularism, and Democracy". In this article researcher put meaning analysis, properties, and development, both in terms of aspirations and the border, from Turkey's ability to exercise "soft power" in its relations with the Arab world. Due to the historical evolutionary process the Turkey's soft power occur Kemalism and Islamism are two symbiotic part of contemporary Turkey. The inner political, economic, and social revolution that begins in the 1970's and 1980 's along with those conveyed about by the end of the cold war are the roots of this process. The question about the soft power perspective in Turkey is that what Turkish soft power can achieve in under enemy control by the multipart balance that Turkey attacks between Islamism and democrat Secularism. There are number of braces that would support the reliability Turkish soft power and would be possible through the continual farming of a balance between secularism, Islam and democracy. On the bases of modernization Turkey develop the economic, technological and industrial growth. Considerable constant economic growth convoyed by progress in social modernization and internal economic and political solidity. Transformed cultural growth through the new creation of universities, museum and also through the broadcasting of television serials, soap operas are having great success in Arab words.

\section{Theoretical Framework}

With the decline of hypodermic needle theories a new perspective began to emerge the stalagmite theories. Black et al. used the metaphor of stalagmite theories to suggest that media effects occur analogously to the slow buildup of formations on cave floors, which take their interesting forms after eons of the steady dripping of limewater from the cave ceilings above. One of the most popular theories that fit this perspective is cultivation theory.

Cultivation theory sometimes referred to as the cultivation hypothesis or cultivation analysis was an approach developed by Professor George Gerbner, dean of the Annenberg School of Communications at the University of Pennsylvania. He began the 'Cultural Indicators research project in the mid-1960s, to study whether and how watching television may influence viewers' ideas of what the everyday world is like. Cultivation research is in the effects tradition. Cultivation theorists argue that television has long-term effects which are small, gradual, indirect but cumulative and significant.

Cultivation theory in its most basic form, suggests that television is responsible for shaping, or cultivating viewers conceptions of social reality. The combined effect of massive television exposure by viewers over time subtly shapes the perception of social reality for individuals and, ultimately, for our culture as a whole. Gerbner argues that the mass media cultivate attitudes and values which are already present in a culture: the media maintain and propagate these values amongst members of a culture, thus binding it together. He has argued that television tends to cultivate middle-of-the- road political perspectives.

Gerbner called this effect mainstreaming. Cultivation theorists distinguish between first order effects general beliefs about the everyday world, such as about the prevalence of violence and second order effects specific attitudes, such as to law and order or to personal safety. There is also a distinction between two groups of television viewers: the heavy viewers and the light viewers. The focus is on heavy viewers.
People who watch a lot of television are likely to be more influenced by the ways in which the world is framed by television programs than are individuals who watch less, especially regarding topics of which the viewer has little first-hand experience. Light viewers may have more sources of information than heavy viewers. Resonance describes the intensified effect on the audience when what people see on television is what they have experienced in life. This double dose of the televised message tends to amplify the cultivation effect.

Cultivation analysis commonly includes the correlation of data from content analysis finding usual images on television with survey data from audience research to measure any influence of such images on the attitudes of viewers.

In this study through drama Turkish develop their culture in the mind of the audiences. When audiences watch dramas on TV then mostly they inspire from TV dramas and try to change their life style according the models of TV dramas. And these things are cultivating in the mind of the audiences. This study proves that those people who watch Turkish dramas are highly influenced by Turkish dramas.

University students are trying to adopt the styles of Turkish dramas models and it is directly cultivating in the minds of University students through Turkish dramas by media. They are trying to adopt the dressing style of these drama models and also influenced by their living style. Turkish dramas are promote liberty among Pakistani women they pretend in their dramas that women should be independent in their nation. And that's way they are changing the views of Pakistani University students according to their own views.

And all these thing are directly cultivating in the mind of the University students because youngsters of any nation mostly affecting from new styles. And media play an important role to change the minds of the people. Media directly hit the mind of the audiences which follow the media mostly. Audience research by cultivation theorists contains asking large-scale public opinion survey organizations to include in their national surveys questions about such issues as the extent of violence in everyday life. Answers are interpreted as reproducing either the world of television or that of everyday life. The answers are then related to the amount of television watched, other media habits and demographic data such as sex, age, income and education.

\section{Methodology}

The process used to collect information and data for the purpose of making business decisions. The methodology may include publication research, interviews, surveys and others research techniques, and could contain both present and historical material. Methodology is the organized, theoretical analysis of the methods useful to a field of study. It comprises the theoretical analysis of the body of methods and principles associated with a branch of knowledge.

Quantitative survey method will use for this research and questionnaire use as a tool of data collection. Population of this research is the Universities of Pakistan data will be collected from three different Universities. And want to check the effects of Turkish dramas on Universities because today Turkish dramas are more presented in Pakistani entertainment channels. Because young generation adopts the modernization rapidly that's way to check effects on young Universities students.

\section{Survey method}

A survey is defined as a brief interview or conversation with individuals about a precise topic. The term survey is unfortunately a 
little unclear, so we need to define it well. The term survey is often used to mean gather information.

\section{Population}

"Population is the total aggregate of elements from where sample is selected on the basis of sampling technique and where researcher is conducted a research". The total number of persons, inhabiting a country, city or any district or area is called population. Population of this study is the students of different Universities of Pakistan.

\section{Target population}

Target population refers to the entire group of individuals or objects to which researchers are interested in simplifying the conclusions. The target population usually has changing characteristics and it is also known as the theoretical population. Aim of this study to investigate the influence of Turkish dramas on the students of different Universities of Pakistan. The target population is University of Gujrat, Arid Agriculture University Rawalpindi and Punjab University Lahore.

\section{Element of the study}

- They are must be the University students in Pakistan.

- They are must be the students of "Gujrat University Gujrat, Punjab University Lahore and Arid Agriculture University Rawalpidi.

\section{Sampling technique}

Sampling technique which used in the research was the simple random sampling. Researcher selects the respondents randomly. In which everyone have equal chance to participate in the research activity?: And survey research was used as sampling procedure of data collection.

\section{Sample size}

In the present study the sample was 300 respondents were selected from the target population. The 100 from University of Gujrat, Gujrat, 100 from Punjab University Lahore and 100 from Quaid-e-Azam University Islamabad.

\section{Tool of data collection}

Questionnaire was used as a tool of data collection in the present study. Close ended questions were used in the questionnaire for the purpose of data collection.

\section{Data Analysis}

In this figure the data analysis explain the Reliability Statistics and Reliability scale, researcher collects data from the three different Universities of Pakistan to know the effects of Turkish dramas on the different areas of Pakistani youngsters.

\section{Reliability scale: Interpretation}

In this research researcher want to know about the "effects of Turkish dramas on University students". Researcher collects data from the three different Universities of Pakistan to know the effects of Turkish dramas on the different areas of Pakistani youngsters. Because in every country the young generation got change in the world and youngsters adopt the new living styles. The first question is about the age because age matter the most in any kind of change. Researcher divided two age groups in every university. The first is $18-21$ and the second is $22-25$ and the results shown that in Gujrat University from the first age group 64 and from second age group 36 respondents give the response of researcher's questions. And the next Arid agriculture University from Rawalpindi the results from first age group is 67 and from second age group 33 respondents give the answers to the researcher's questions. The third and last University from which data is collected is Punjab University of Lahore and the results are same from Rawalpindi and Lahore the first age group respondents are 67 and from second age group respondents are 33 who give the response to researcher's questions (Figure 1).

\section{University: Interpretation}

In this research researcher want to investigate the "effects of Turkish dramas on University students. For this purpose data collected from the different Universities of Pakistan. As we know that that from dramas and anything new is directly effects the young generation of any nation that's way researcher want to study the Turkish drama effects on young generation of the Pakistan. And in this research researcher choose three hundred sample sizes and divide it into three different Universities of Pakistan 100 respondents selected from the University of Gujrat, Gujrat, 100 respondents were chosen from Punjab University Lahore and 100 from the Arid Agriculture University Rawalpindi (Figure 2).

\section{Do you watch Television?: Interpretation}

In this research researcher want to investigate that the "effects of Turkish dramas on University students". For this topic it is necessary that every respondent must watch the television. To investigate the Turkish drama effects on University students it is must that the respondents are must watch the television then the research is totally fully investigated. And from the three different Universities of Pakistan

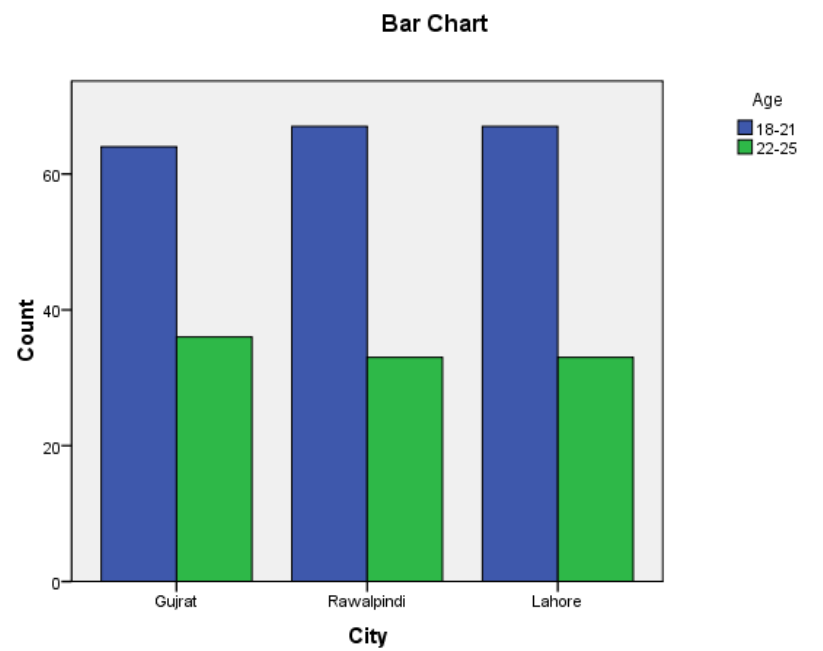

\begin{tabular}{|c|c|c|c|c|}
\hline \multicolumn{3}{|c|}{ Reliability Statistics } \\
\hline \multicolumn{3}{|c|}{ Cronbach's Alpha } & \multicolumn{3}{c|}{ N of Items } \\
\hline \multicolumn{3}{|c|}{0.687} & \multicolumn{3}{c|}{ Age } \\
\hline \multirow{2}{*}{ City } & Gujrat & $18-21$ & $22-25$ & \\
\hline & Rawalpindi & 67 & 36 & 100 \\
\hline & Lahore & 67 & 33 & 100 \\
\hline \multirow{2}{*}{ Total } & & 198 & 102 & 100 \\
\hline
\end{tabular}

Figure 1: Reliability scale. 
who must watch the television give the response to the researcher questions (Figure 3).

\section{Do you watch TV dramas?: Interpretation}

In this research researcher want to know the effects of Turkish dramas on university students. For this purpose data is collected from different Universities of Pakistan. And in this research three Universities of Pakistan were selected from all over Pakistan like

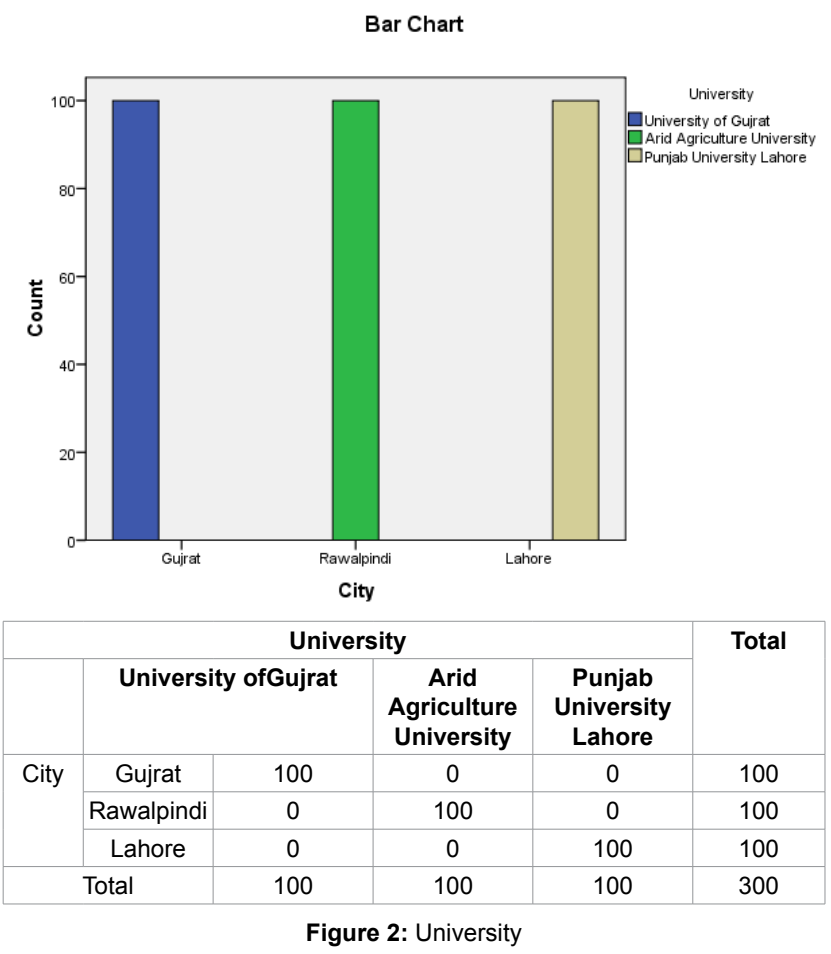

Bar Chart

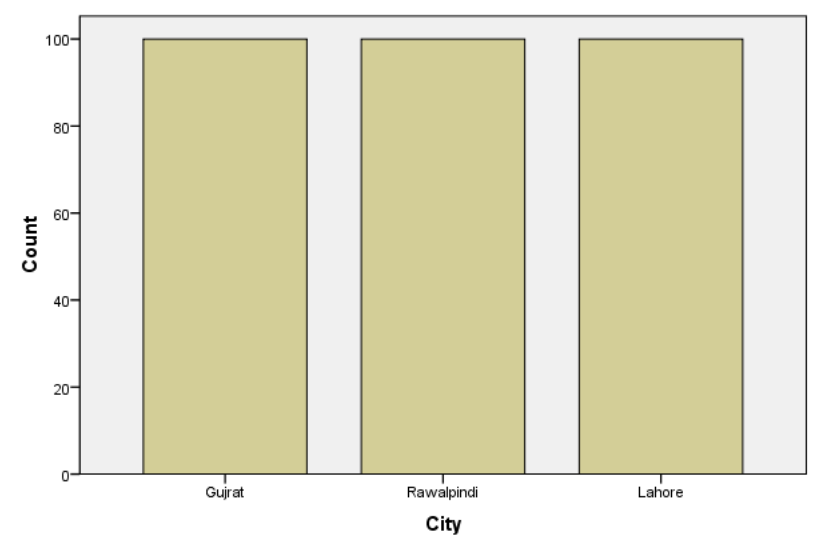

\begin{tabular}{|c|c|c|c|}
\hline \multicolumn{3}{|c|}{ Do you watch television? } \\
\hline \multirow{3}{*}{ City } & Yes & Total \\
\cline { 2 - 4 } & Gujrat & 100 & 100 \\
\cline { 2 - 4 } & Rawalpindi & 100 & 100 \\
\cline { 2 - 4 } & Lahore & 100 & 100 \\
\hline \multirow{2}{*}{ Total } & 300 & 300 \\
\hline
\end{tabular}

Figure 3: Do you watch Television?
University of Gujrat, Gujrat, Punjab University Lahore and Arid Agriculture University Rawalpindi. Total 300 sample size was selected for this research purpose 100 from Gujrat 100 from Lahore and 100 from Rawalpindi (Figure 4).

\section{Do you watch Turkish dramas?: Interpretation}

In this research researcher want to know the effects of Turkish dramas on University students and data were collected from three Universities of Pakistan. Data were collected from those students who are watching Turkish dramas. The next question is asked from the respondents do you watch Turkish dramas. And only those respondents were choosing for this research who watches Turkish dramas. All 300 respondents are given the response that they are watching Turkish dramas. And 100 respondents of Gujrat University give response they are watching Turkish dramas 100 from Punjab University and 100 from Arid Agriculture University of Rawalpindi (Figure 5).

\section{Do you think Turkish dramas present Islamic values?} Interpretation

In this research researcher want to know the effects of Turkish dramas on University students.

As we know that if we know the effects of Turkish dramas on Pakistani University students then it must that researcher collect data from the different Universities of Pakistan. The next is that do you think Turkish dramas present Islamic values?: The first University is University of Gujrat from this University 21 respondents give answer that Turkish dramas are presenting Islamic values and 79 respondents said that Turkish are not presenting the Islamic values total 100 respondents give the answer. Second University is Arid Agriculture University Rawalpindi and 15 respondents said that Islamic values are presenting in Turkish dramas 85 respondents said that Islamic values are not presenting in Turkish dramas. The third University is Punjab University Lahore 32 respondents said that in Turkish dramas Islamic values were presenting and 68 respondents said that Islamic values are

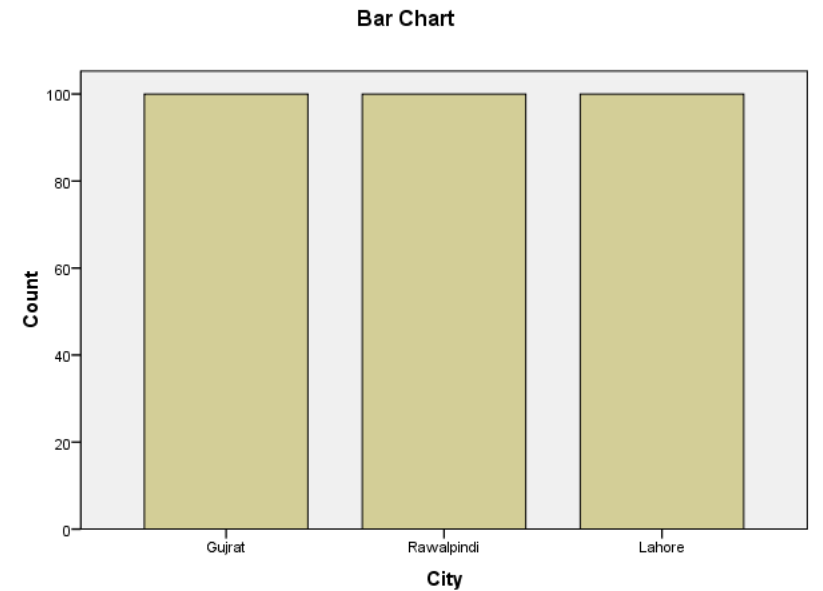

\begin{tabular}{|c|c|c|c|}
\hline \multicolumn{3}{|c|}{ Do you watch TV dramas? } \\
\hline \multirow{3}{*}{ City } & Ges & Total \\
\cline { 2 - 4 } & Gajrat & 100 & 100 \\
\cline { 2 - 4 } & Rawalpindi & 100 & 100 \\
\cline { 2 - 4 } & Lahore & 100 & 100 \\
\hline \multirow{2}{*}{ Total } & 300 & 300 \\
\hline
\end{tabular}

Figure 4: Do you watch TV dramas? 


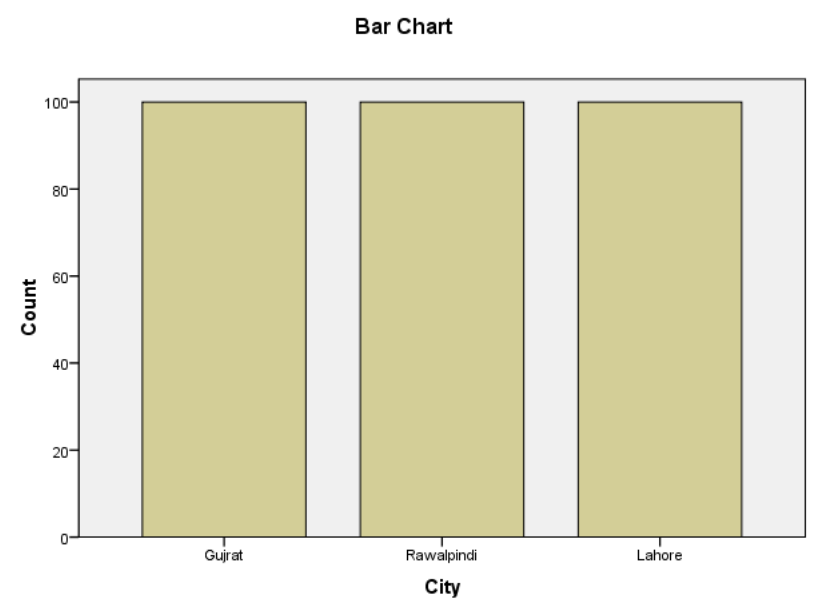

\begin{tabular}{|c|c|c|c|}
\hline \multicolumn{3}{|c|}{ Do you watch Turkish dramas? } \\
\hline \multirow{3}{*}{ City } & Yes & Total \\
\cline { 2 - 4 } & Gujrat & 100 & 100 \\
\cline { 2 - 4 } & Rawalpindi & 100 & 100 \\
\cline { 2 - 4 } & Lahore & 100 & 100 \\
\hline \multicolumn{2}{|c|}{ Total } & 300 & 300 \\
\hline
\end{tabular}

Figure 5: Do you watch Turkish dramas?

not presenting in Turkish Dramas. Total 300 respondents in which 68 respondents said that Turkish dramas present Islamic values and 232 respondents said that Turkish dramas do not present Islamic values. Hence it proves that Turkish dramas do not present Islamic values (Figure 6).

Do you follow the styles of Turkish drama models?: Interpretation

In this research researcher want to know the effects of Turkish dramas on University students. In this research researcher collect data from three different universities of Pakistan like University of Gujrat, Gujrat, Punjab University Lahore and Arid Agriculture University Rawalpindi. Total 300 sample size was selected and 100 respondents were chosen from every University of Pakistan. For this research purpose the next question asked from the students is do you follow the styles of Turkish drama models?: The first data collected from University of Gujrat and 12 respondents said that they are follow the styles of Turkish drama models but 88 respondents said that they do not follow the styles of Turkish drama models. Secondly data collected from Arid Agriculture University Rawalpindi and also 100 respondents from that University and 11 respondents said that they are follow this drama models and 89 respondents said that they do not follow the styles of Turkish drama models styles. Thirdly data collected from the Punjab University Lahore were 26 said that they are follow Turkish drama models style and 74 respondents aid that they are not follow the styles of Turkish dramas models. Total 300 respondents in which 49 respondents said that they are follow the styles of Turkish drama models and 251 respondents said that that they do not follow the styles of Turkish drama models. Hence it proves that they do not follow the styles of Turkish drama models (Figure 7).

\section{Do you think Turkish dramas affect your Islamic values?: Interpretation}

In this research researcher want to know that the effects of Turkish dramas on University students. For this research next question is

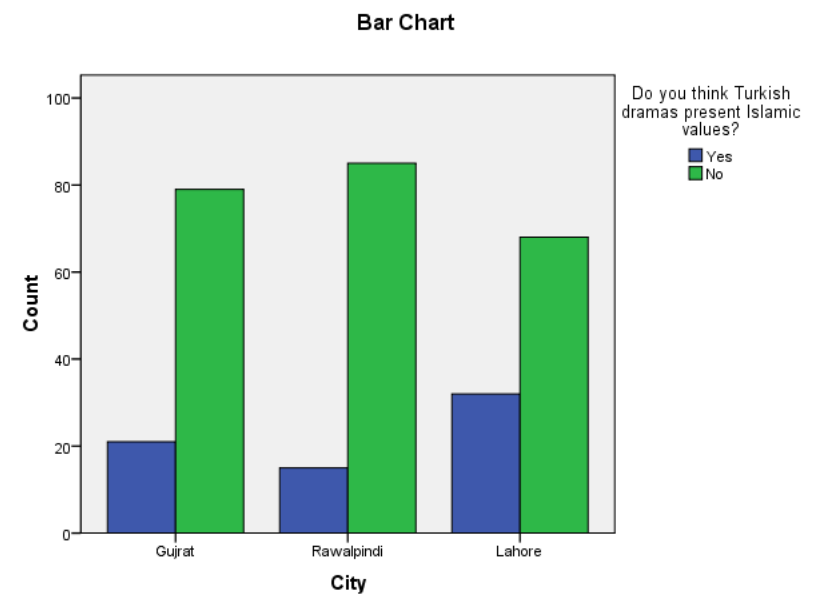

\begin{tabular}{|c|c|c|c|c|}
\hline \multicolumn{5}{|c|}{ Do you think Turkish dramas present Islamic values? } \\
\hline \multirow{3}{*}{ City } & & Yes & No & \\
\cline { 2 - 5 } & Gujrat & 21 & 79 & 100 \\
\cline { 2 - 5 } & Rawalpindi & 15 & 85 & 100 \\
\cline { 2 - 5 } & Lahore & 32 & 68 & 100 \\
\hline \multirow{2}{*}{ Total } & 300 & 300 & \\
\hline
\end{tabular}

Figure 6: Do you think Turkish dramas present Islamic values?

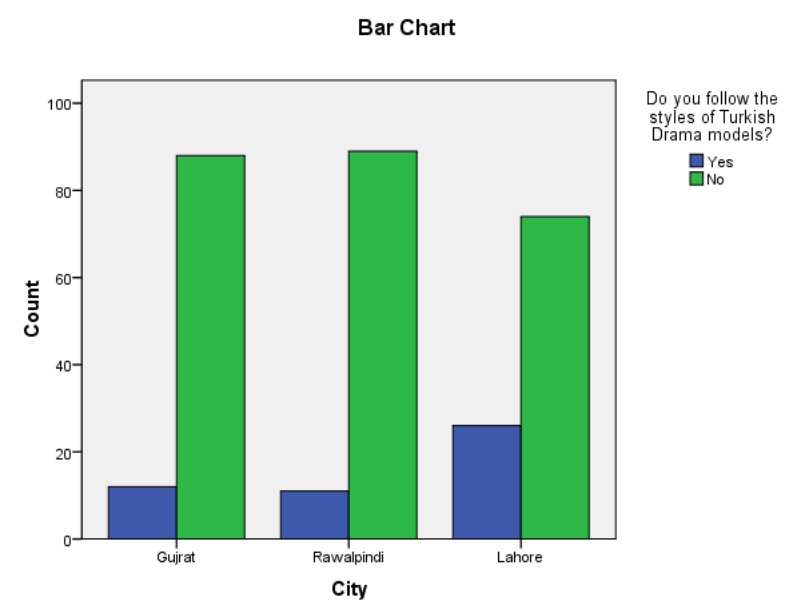

\begin{tabular}{|c|c|c|c|c|}
\hline \multicolumn{5}{|c|}{ Do you follow the styles of Turkish Drama models? } \\
\hline \multirow{3}{*}{ City } & & Yes & No & \\
\cline { 2 - 5 } & Gujrat & 12 & 88 & 100 \\
\cline { 2 - 5 } & Rawalpindi & 11 & 89 & 100 \\
\cline { 2 - 5 } & Lahore & 26 & 74 & 100 \\
\hline \multirow{2}{*}{ Total } & 49 & 251 & 300 \\
\hline
\end{tabular}

Figure 7: Do you follow the styles of Turkish drama models?

"do you think Turkish dramas affect your Islamic values"?: In Gujrat University 52 respondents said that Turkish dramas affect Islamic values and 48 respondents said that Turkish dramas are not affect Islamic values. In Rawalpindi University 51 respondents said that Turkish dramas are affect Islamic values and 49 respondents said that Turkish dramas do not affect Islamic values and from third and last University is Punjab University in which 49 respondents said that Turkish dramas are affects Islamic values and 51 respondents said that Turkish dramas do not affects Islamic values. And total 300 respondents in which 152 
respondents said that Turkish dramas affect the Islamic values and 148 respondents said that Turkish dramas do not affects the Islamic values (Figure 8).

\section{Do you think Turkish dramas are best source of entertainment?: Interpretation}

In this research researcher want to investigate about effects of Turkish dramas on University students. Especially youngsters affect from dramas and they adopt the modern life styles. The next question about this research is "do you think Turkish dramas are best source of entertainment". From first University of Gujrat in which 28 respondents said that Turkish dramas are best source of entertainment and 72 respondents said that Turkish dramas are not best source of entertainment. Second category is Arid Agriculture University Rawalpindi in which 37 respondents said that Turkish dramas are best source of entertainment and 63 respondents give response that Turkish are not best source of entertainment and third and last category is Punjab University Lahore in which 46 respondents give response that Turkish dramas are best source of entertainment and 54 respondents said that Turkish dramas are not best source of entertainment. Total 300 respondents in which 111 respondents said Turkish dramas are best source of entertainment and 189 said not. It proves that Turkish dramas are best source of entertainment (Figure 9).

\section{Do you think Turkish dramas are changing the dressing style of University students?: Interpretation}

In this research researcher want to know about effects of Turkish dramas on University students. Researcher collects data from three different Universities of Pakistan from different areas of Pakistan. And these Universities are University of Gujrat, Gujrat, Arid Agriculture University Rawalpindi and Punjab University Lahore. Next question about this study is "do you think Turkish dramas are changing the dressing style of University students". Firstly collet data from University of Gujrat in which 56 respondents give answer that due to Turkish dramas dressing style changing in University students and

Bar Chart

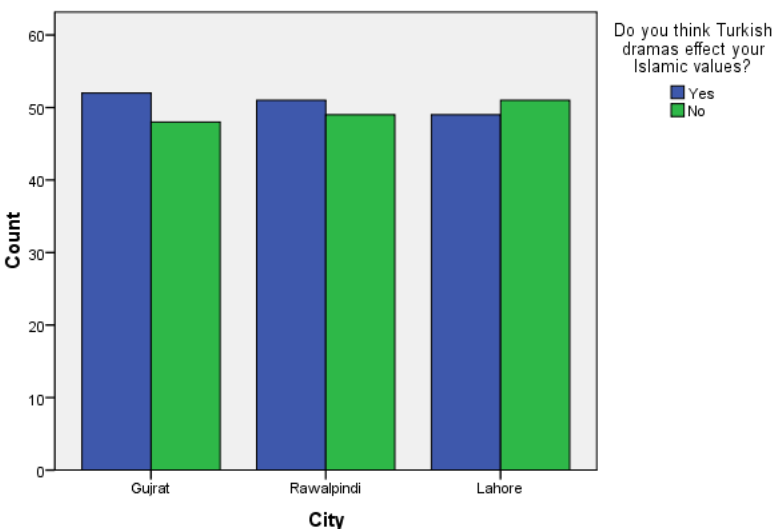

Do you think Turkish dramas affect your Islamic values?

\begin{tabular}{|c|c|c|c|c|}
\hline \multirow{3}{*}{ City } & & Yes & No & \\
\cline { 2 - 5 } & Gujrat & 52 & 48 & 100 \\
\cline { 2 - 5 } & Rawalpindi & 51 & 49 & 100 \\
\cline { 2 - 5 } & Lahore & 49 & 51 & 100 \\
\hline \multirow{2}{*}{ Total } & 152 & 148 & 300 \\
\hline
\end{tabular}

Figure 8: Do you think Turkish dramas affect your Islamic values?

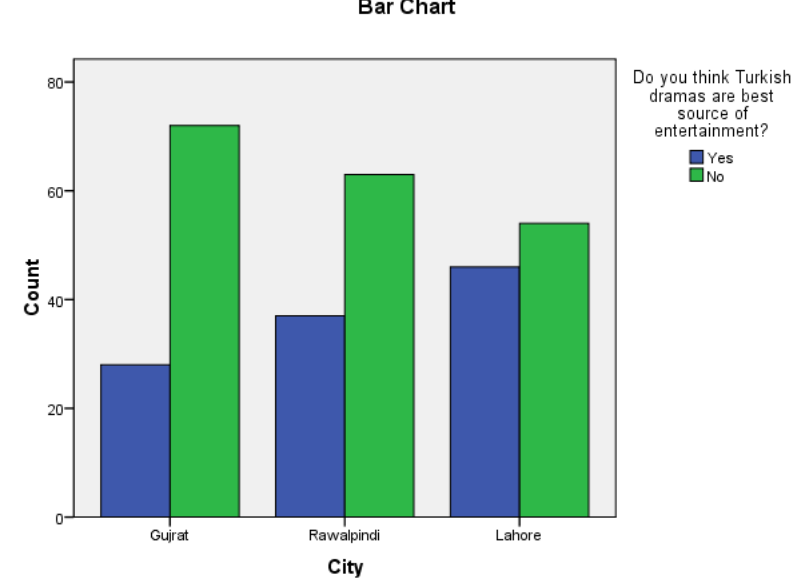

\begin{tabular}{|c|c|c|c|c|}
\hline \multicolumn{5}{|c|}{ Do you think Turkish dramas are best source of entertainment? } \\
\hline & & Yes & No & \\
\hline \multirow[t]{3}{*}{ City } & Gujrat & 28 & 72 & 100 \\
\hline & Rawalpindi & 37 & 63 & 100 \\
\hline & Lahore & 46 & 54 & 100 \\
\hline \multicolumn{2}{|c|}{ Total } & 111 & 189 & 300 \\
\hline
\end{tabular}

Figure 9: Do you think Turkish dramas are best source of entertainment?

44 respondents give response that Turkish dramas are not changing dressing style in University students. Secondly data collected from Arid Agriculture University Rawalpindi in which 53 respondents said that Turkish dramas are changing dressing style in University students and 47 respondents said that Turkish dramas are not changing dressing style among University students. Thirdly data collected from Punjab University Lahore in which 63 respondents said that Turkish dramas are changing dressing styles of University students and 37 respondents said that Turkish dramas are not changing dressing styles of University students. Total 300 respondents in which 172 respondents are in favor of this question and 128 respondents are not in favor of this question. It proves that Turkish dramas are changing dressing styles of University students (Figure 10).

\section{Do you think Pakistani TV channels are promoting Turkish Dramas?: Interpretation}

In this research researcher want to know about the "effects of Turkish dramas on University students". This study selects three different Universities of Pakistan from three different areas of Pakistan like University of Gujrat, Gujrat, Arid Agriculture University Rawalpindi and Punjab University Lahore. One more question asks to respondents for this study is "do you think Pakistani TV channels are promoting Turkish dramas". Firstly show the responses of University of Gujrat in which 75 respondents said that Pakistani TV channels are promoting Turkish dramas and 25 respondents said that Pakistani TV channels are not promoting Turkish dramas. Secondly data collected from Arid Agriculture University Rawalpindi in which 76 respondents said that Pakistani TV channels are promoting Turkish dramas and 24 respondents give response that Pakistani TV channels are not promoting Turkish dramas. Lastly data collected from Punjab University Lahore in which 81 respondents said that Pakistani TV channels are promoting Turkish dramas and 19 respondents said that Pakistani TV channels are not promoting Turkish dramas. Total 232 respondents said that Pakistani TV channels are promoting Turkish dramas and 68 respondents said that not promoting. Hence prove that 


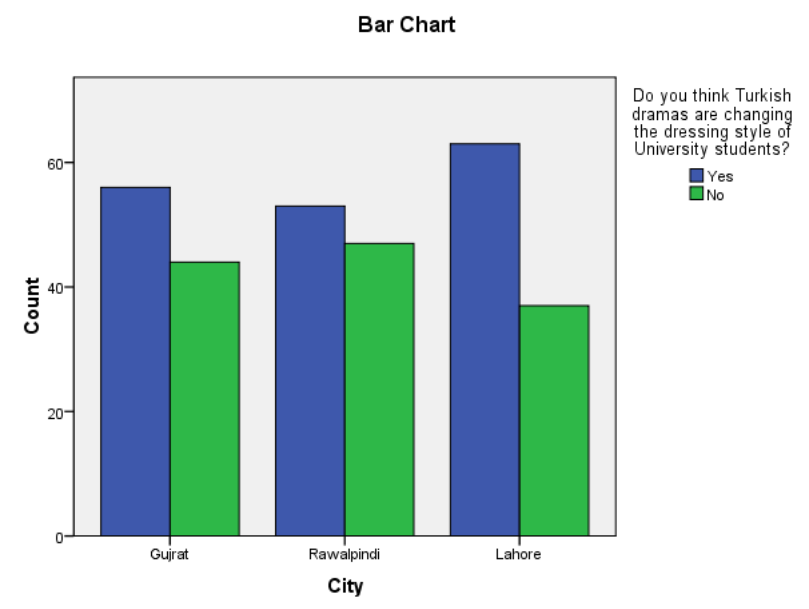

\begin{tabular}{|c|c|c|c|c|}
\hline \multicolumn{4}{|c|}{ Do you think Turkish dramas are changing the dressing style of } \\
University students? Cross tabulation \\
\hline \multirow{3}{*}{ City } & & Yes & No & \\
\cline { 2 - 5 } & Gujrat & 56 & 44 & 100 \\
\cline { 2 - 5 } & Rawalpindi & 53 & 47 & 100 \\
\cline { 2 - 5 } & Lahore & 63 & 37 & 100 \\
\hline & Total & 172 & 128 & 300 \\
\hline
\end{tabular}

Figure 10: Do you think Turkish dramas are changing the dressing style of University students?

Pakistani TV channels are promoting Turkish dramas (Figure 11).

\section{Do you think Turkish dramas are influenced by Western culture?: Interpretation}

In this research researcher want to investigate about the "effects of Turkish dramas on University students". Next question asks about this research is "do you think Turkish dramas are influenced by Western culture". For this study purpose researcher collect data from three different Universities of Pakistan which helps to know the responses of University students especially the youngsters of Pakistani nation. Dramas are the powerful instruments to entertain and change the views of any nation's viewers or audiences. Firstly data collected from the University of Gujrat in which 79 respondents said that Turkish dramas are influenced by Western culture and they publish mostly the Western content in their dramas and 21 respondents said that Turkish dramas do not influenced by Western culture. Secondly data collected from Arid Agriculture University Rawalpindi in which 87 respondents said that Turkish dramas are influenced by Western culture and 13 respondents said that Turkish dramas are not influenced by Western culture they prefer the Muslim content in their dramas. Lastly data collected from Punjab University Lahore in which 70 respondents said that Turkish dramas are influenced by Western culture and 30 respondents said that Turkish dramas are not influenced by Western culture. Total 300 respondents in which 236 respondents said that Turkish dramas are influenced by Western culture and 64 respondents said they do not. Hence it proves that Turkish dramas are influenced by Western culture (Figure 12).

\section{Do you think Turkish dramas promote liberty among Pakistani women?: Interpretation}

In this research researcher want to investigate the "effects of Turkish dramas on University students". In this research researcher collect data from three Universities of Pakistan to know the effects of

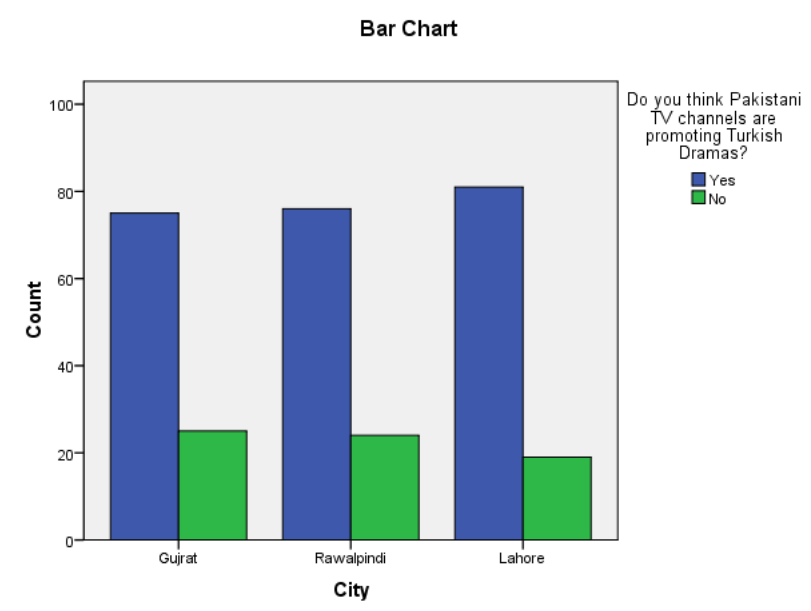

\begin{tabular}{|c|c|c|c|c|}
\hline \multicolumn{5}{|c|}{ Do you think Pakistani TV channels are promoting Turkish Dramas? } \\
\hline \multirow{3}{*}{ City } & & Yes & No & \\
\cline { 2 - 5 } & Gujrat & 75 & 25 & 100 \\
\cline { 2 - 5 } & Rawalpindi & 76 & 24 & 100 \\
\cline { 2 - 5 } & Lahore & 81 & 19 & 100 \\
\hline \multirow{2}{*}{ Total } & 232 & 68 & 300 \\
\hline
\end{tabular}

Figure 11: Do you think Pakistani TV channels are promoting Turkish Dramas?

\section{Bar Chart}

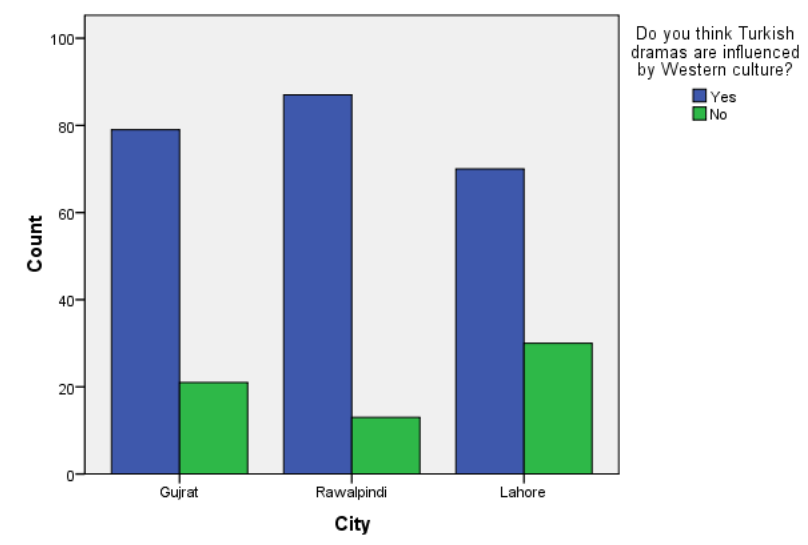

\begin{tabular}{|c|c|c|c|c|}
\hline \multicolumn{5}{|c|}{ Do you think Turkish dramas are influenced by Western culture? } \\
\hline \multirow{3}{*}{ City } & & Yes & No & \\
\cline { 2 - 5 } & Gujrat & 79 & 21 & 100 \\
\cline { 2 - 5 } & Rawalpindi & 87 & 13 & 100 \\
\cline { 2 - 5 } & Lahore & 70 & 30 & 100 \\
\hline \multicolumn{2}{|c|}{ Total } & 236 & 64 & 300 \\
\hline
\end{tabular}

Figure 12: Do you think Turkish dramas are influenced by Western culture?

Turkish dramas on University students in Pakistan. Three Universities like University of Gujrat, Arid Agriculture University Rawalpindi and Punjab University Lahore are selected for this research. Next question fir this research is "do you think Turkish dramas are promote liberty among Pakistani women". Firstly data collected from University of Gujrat total 100 respondents selected in which 65 respondents said that Turkish dramas promote liberty among Pakistani women and 35 respondents said that Turkish dramas are not promote liberty among Pakistani women. Secondly data collected from Arid 
agriculture University Rawalpindi in which 66 respondents said that Turkish dramas are promote liberty among Pakistani women and 34 respondents said that Turkish dramas are not promote liberty among Pakistani women. Thirdly data collected from Punjab University Lahore in which 70 respondents said that Turkish dramas promote liberty among Pakistani women and 30 respondents said that Turkish dramas are not promote liberty among Pakistani women. Total 300 respondents are selected in which 201 respondents said that Turkish dramas are promote liberty among women and 99 respondents said that Turkish dramas are not promote liberty among Pakistani women. Hence it proves that Turkish dramas promote liberty among Pakistani women (Figure 13).

Do you think Turkish dramas presentation portrayal of women by media in accordance with Islam?: Interpretation

In this research researcher want to know the "effects of Turkish dramas on University students". This research depends on Pakistani nation and data collected from three different Universities of Pakistan. The next question about this research is "do you think Turkish dramas are presenting portrayal of women by media in accordance with Islam". Firstly data collected from University of Gujrat in which 26 respondents said that Turkish dramas are presenting portrayal of women by media in accordance with Islam and 74 respondents said that Turkish dramas are not presenting portrayal of women by media in accordance with Islam. Secondly data collected from Arid Agriculture University Rawalpindi in which 22 respondents said that Turkish dramas are presenting portrayal of women by media in accordance with Islam and 78 respondents said that Turkish dramas are not presenting portrayal of women by media in accordance with Islam. Thirdly data collected from Punjab University Lahore in which 30 respondents said that Turkish dramas presenting portrayal of women by media in accordance with Islam and 70 respondents said that Turkish dramas are not presenting portrayal of women by media in accordance with Islam. Total 300

Bar Chart

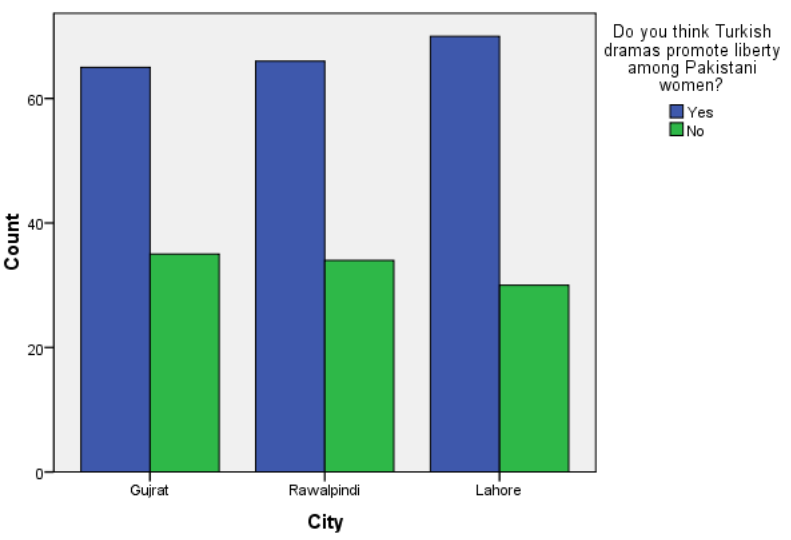

Do you think Turkish dramas promote liberty among Pakistan

\begin{tabular}{|c|c|c|c|c|}
\hline \multicolumn{4}{|c|}{ women? } \\
\hline \multirow{3}{*}{ City } & & Yes & No & \\
\cline { 2 - 5 } & Gujrat & 65 & 35 & 100 \\
\cline { 2 - 5 } & Rawalpindi & 66 & 34 & 100 \\
\cline { 2 - 5 } & Lahore & 70 & 30 & 100 \\
\hline \multirow{2}{*}{ Total } & 201 & 99 & 300 \\
\hline
\end{tabular}

Figure 13: Do you think Turkish dramas promote liberty among Pakistani women? respondents in which 78 respondents said that Turkish dramas are presenting portrayal of women by media in accordance with Islam and 222 respondents said that Turkish dramas are not presenting portrayal of women by media in Islam. Hence prove that Turkish dramas are not presenting portrayal of women by media in accordance with Islam (Appendices 1-3) (Figure 14).

\section{Do you think life style in Turkish dramas is according to Islam?: Interpretation}

In this research researcher want to investigate the "effects of Turkish dramas on University students". The next question about this research is "Do you think life style in Turkish dramas is according to Islam". In this research data collected from three different Universities of Pakistan like University of Gujrat, Arid Agriculture University Rawalpindi and Punjab University Lahore. Firstly data collected from University of Gujrat in which 16 respondents said that life style in Turkish dramas is according to Islam and 84 respondents said that life style in Turkish dramas is not according to Islam. Secondly data collected from Arid Agriculture University Rawalpindi in which 16 respondents said that life style in Turkish dramas is according to Islam and 84 respondents said that life style in Turkish dramas is not according to Islam both Universities researcher get same responses. Lastly data collected from Punjab University Lahore in which 29 respondents said that life style in Turkish dramas is according to Islam and 71 respondents said that life style in Turkish dramas is not according to Islam. Total 300 respondents in which 61 respondents give response that life style in Turkish dramas is according to Islam and 239 give response that life style in Turkish dramas is not according to Islam. Hence prove that life style in Turkish dramas is not according to Islam (Figure 15).

\section{Do you think the dress code in Turkish dramas is according to Islam?: Interpretation}

In this research researcher investigate the "effects of Turkish dramas

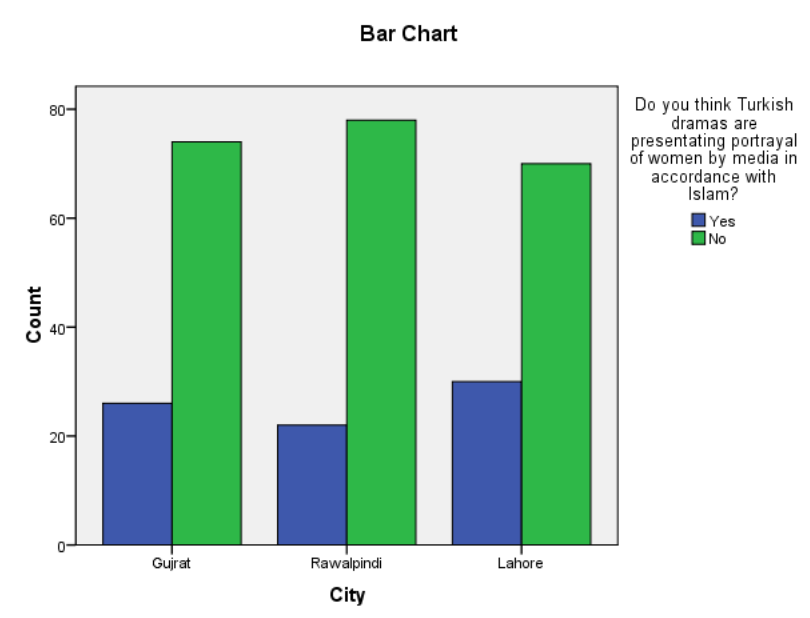

\begin{tabular}{|c|c|c|c|c|}
\hline \multicolumn{5}{|c|}{ Do you think Turkish dramas are presenting portrayal of women by } \\
media in accordance with Islam?
\end{tabular}

Figure 14: Do you think Turkish dramas presentation portrayal of women by media in accordance with Islam? 


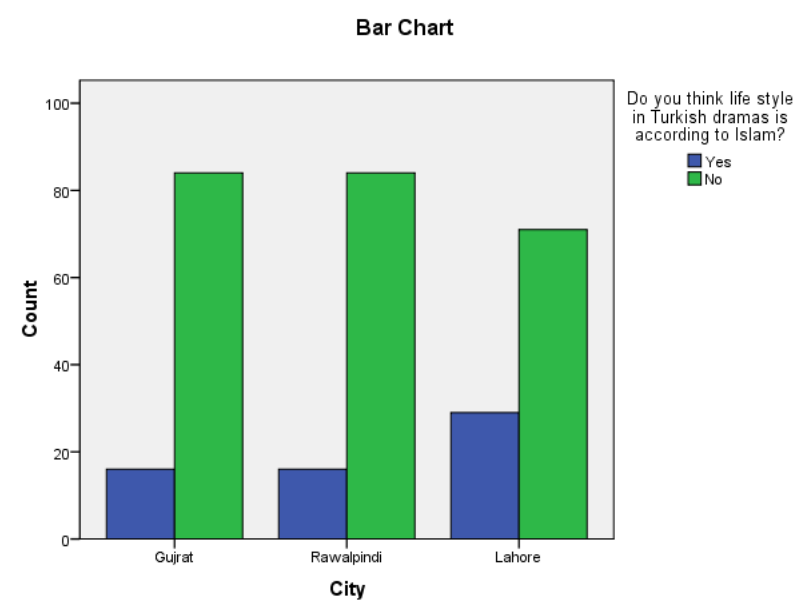

\begin{tabular}{|l|c|c|c|c|}
\multicolumn{5}{|c|}{ Do you think life style in Turkish dramas is according to Islam? } \\
\hline \multirow{3}{*}{ City } & Ges & No & \\
\cline { 2 - 5 } & Gujrat & 16 & 84 & 100 \\
\cline { 2 - 5 } & Rawalpindi & 16 & 84 & 100 \\
\cline { 2 - 5 } & Lahore & 29 & 71 & 100 \\
\hline \multirow{2}{*}{ Total } & 61 & 239 & 300 \\
\hline
\end{tabular}

Figure 15: Do you think life style in Turkish dramas is according to Islam?

in University students". The next question about this research is "Do you think the dress code in Turkish dramas is according to Islam". Data collected from three Universities of Pakistan from Gujrat, Rawalpindi and Lahore. Firstly data collected from University of Gujrat in which 13 respondents said that the dress code in Turkish dramas is according to Islam and 87 respondents said that the dress code in Turkish dramas is not according to Islam. Secondly data collected from Arid Agriculture University Rawalpindi in which 16 respondents said that the dress code in Turkish dramas is according to Islam and 84 respondents said that the dress code in Turkish dramas is not according to Islam. Lastly data collected from Punjab University Lahore in which 24 respondents said that the dress code in Turkish dramas is according to Islam and 76 respondents said that the dress code in Turkish dramas is not according to Islam. Total 300 respondents in which 53 respondents give response that dress code in Turkish dramas is according to Islam and 247 give response that dress code in Turkish dramas is not according to Islam. Hence prove that the dress code in Turkish dramas is not according to Islam (Figure 16).

\section{How many hours do you watch TV?: Interpretation}

In this research researcher want to investigate the "effects of Turkish dramas on University students". Next question about this research is "How many hours do you watch TV". Firstly data collected from University of Gujrat in which 38 respondents said that they are watching TV 1 hours per day, 25 respondents said that they are watching TV 2 hours per day, 29 respondents said that they are watching TV 3 hours per day, 3 respondents said that they are watching TV 4 hours per day and 5 respondents said that they are watching TV more than 4 hours per day. Secondly data collected from Arid Agriculture University Rawalpindi in which 29 respondents said that they are watching TV 1 hour per day, 29 respondents said that they are watching TV 2 hours per day, 26 respondents said that they are watching TV 3 hours per day, 8 respondents said that they are watching TV 4 hours per day and 8 respondents said that they are watching TV more than 4 hours per day. Thirdly data collected from Punjab University Lahore in which 19 respondents said that they are watching
TV 1 hour per day, 43 respondents said that they are watching TV 2 hours per day, 26 respondents said that they are watching TV 3 hours per day, 5 respondents said that they are watching TV 4 hours per day and 7 respondents said that they are watching TV more than 4 hours. Total 300 respondents in which 86 respondents said that they are watching TV 1 hour, 97 said that they are watching TV 2 hours, 81 respondents said that they are watching TV 3 hours, 16 respondents said that they are watching TV 4 hours, and 20 respondents said that they are watching TV more than 4 hours. It is prove that mostly respondents watch TV 2 hours in a day (Figure 17).

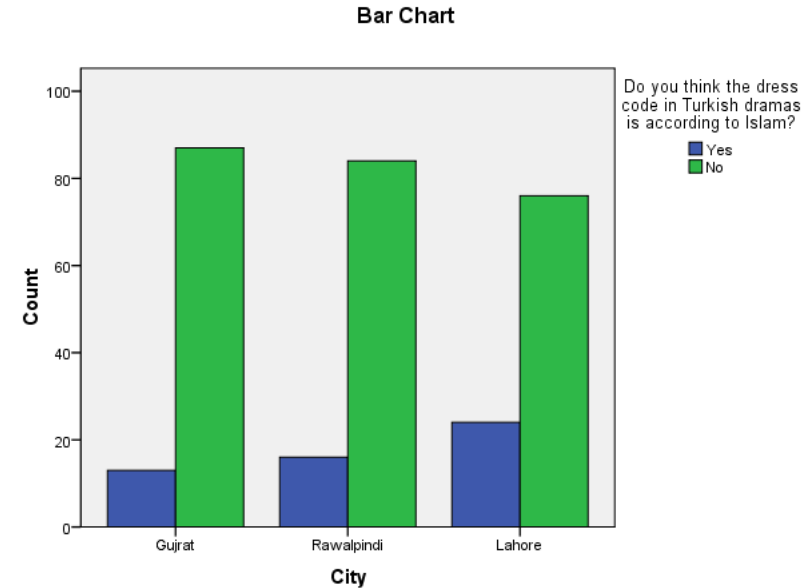

\begin{tabular}{|c|c|c|c|c|}
\hline \multicolumn{5}{|c|}{ Do you think the dress code in Turkish dramas is according to Islam? } \\
\hline \multirow{3}{*}{ City } & & Yes & No & \\
\cline { 2 - 5 } & Gujrat & 13 & 87 & 100 \\
\cline { 2 - 5 } & Rawalpindi & 16 & 84 & 100 \\
\cline { 2 - 5 } & Lahore & 24 & 76 & 100 \\
\hline \multirow{2}{*}{ Total } & 53 & 247 & 300 \\
\hline
\end{tabular}

Figure 16: Do you think the dress code in Turkish dramas is according to Islam?

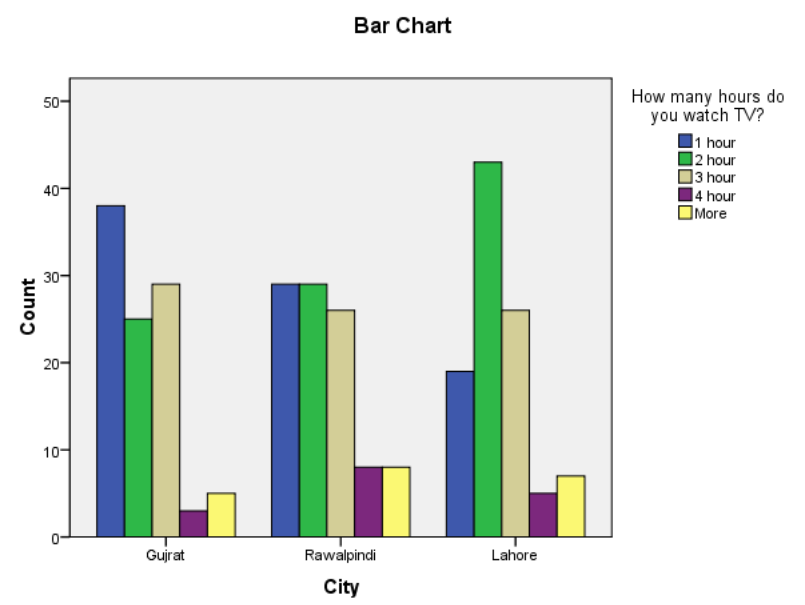

\begin{tabular}{|c|c|c|c|c|c|c|c|}
\hline \multicolumn{7}{|c|}{ How many hours do you watch TV? } \\
\hline \multirow{2}{*}{ City } & 1 hour & $\mathbf{2}$ hour & $\mathbf{3}$ hour & $\mathbf{4}$ hour & More & \\
\cline { 2 - 9 } & Gujrat & 38 & 25 & 29 & 3 & 5 & 100 \\
\cline { 2 - 9 } & Rawalpindi & 29 & 29 & 26 & 8 & 8 & 100 \\
\cline { 2 - 9 } & Lahore & 19 & 43 & 26 & 5 & 7 & 100 \\
\hline \multicolumn{2}{|c|}{ Total } & 86 & 97 & 81 & 16 & 20 & 300 \\
\hline
\end{tabular}

Figure 17: How many hours do you watch TV? 


\section{How many hours do you watch Turkish dramas?: Interpretation}

In this research researcher want to investigate the "effects of Turkish dramas on University students". For this research data collect from three Universities of Pakistan. Next question about this research is "How many hours do you watch Turkish dramas". Firstly data collected from University of Gujrat in which 73 respondents said that they are watching Turkish dramas 1 hours per day, 24 respondents said that they are watching Turkish dramas 2 hours per day, 2 respondents said that they are watching Turkish dramas 3 hours per day, 1 respondents said that they are watching Turkish dramas 4 hours per day and 0 respondents said that they are watching Turkish dramas more than 4 hours per day. Secondly data collected from Arid Agriculture University Rawalpindi in which 75 respondents said that they are watching Turkish dramas 1 hour per day, 13 respondents said that they are watching Turkish dramas 2 hours per day, 5 respondents said that they are watching Turkish dramas 3 hours per day, 1 respondents said that they are watching Turkish dramas 4 hours per day and 6 respondents said that they are watching Turkish dramas more than 4 hours per day. Thirdly data collected from Punjab University Lahore in which 64 respondents said that they are watching Turkish dramas 1 hour per day, 29 respondents said that they are watching Turkish dramas 2 hours per day, 4 respondents said that they are watching Turkish dramas 3 hours per day, 1 respondents said that they are watching Turkish dramas 4 hours per day and 2 respondents said that they are watching Turkish dramas more than 4 hours. Total 300 respondents in which 212 respondents said that they are watching Turkish dramas 1 hour, 66 said that they are watching Turkish dramas 2 hours, 11 respondents said that they are watching Turkish dramas 3 hours, 3 respondents said that they are watching Turkish dramas 4 hours, and 8 respondents said that they are watching Turkish dramas more than 4 hours. Now prove that mostly respondents watch Turkish dramas one hour per day (Figure 18).

Bar Chart

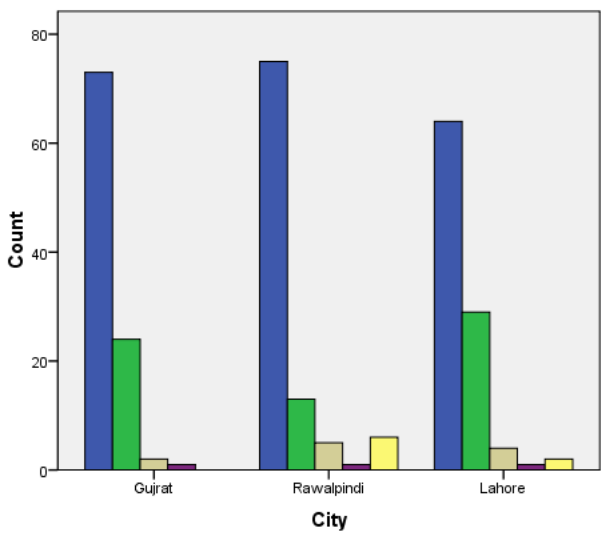

How many hours do you watch Turkish dramas?

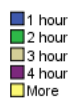

\begin{tabular}{|c|c|c|c|c|c|c|c|}
\hline \multicolumn{8}{|c|}{ How many hours do you watch Turkish dramas? } \\
\hline & & 1 hour & 2 hour & 3 hour & 4 hour & More & \\
\hline \multirow[t]{3}{*}{ City } & Gujrat & 73 & 24 & 2 & 1 & 0 & 100 \\
\hline & Rawalpindi & 75 & 13 & 5 & 1 & 6 & 100 \\
\hline & Lahore & 64 & 29 & 4 & 1 & 2 & 100 \\
\hline \multicolumn{2}{|r|}{ Total } & 212 & 66 & 11 & 3 & 8 & 300 \\
\hline
\end{tabular}

Figure 18: How many hours do you watch Turkish dramas?

\section{Which kind of culture is promoted by Turkish dramas?: Interpretation}

In this research researcher want to investigate the "effects of Turkish dramas on University students". In this study researcher collect data from three different Universities of Pakistan i.e., University of Gujrat, Arid Agriculture University Rawalpindi and Punjab University Lahore. Next study for this research is "Which kind of culture is promoted by Turkish dramas". Firstly data collected from University of Gujrat in which 15 respondents said that Turkish dramas are promoting Pakistani culture, 1 respondent said that Turkish drama promote Hindi culture in their dramas and 84 respondents said that Turkish dramas promote Western culture. Secondly data collected from Arid Agriculture University Rawalpindi in which 6 respondents said that Turkish dramas promote Pakistani culture, 2 respondents said that Turkish dramas promote Hindi Culture in their dramas and 92 respondents said that Turkish dramas promote Western culture. Thirdly data collected from Punjab University Lahore in which 17 respondents said that Turkish dramas promote Pakistani culture, 11 respondents said that Turkish dramas promote Hindi culture and 72 respondents said that Turkish dramas are promote Western culture in their dramas. Total 300 respondents in which 38 respondents said that Turkish dramas promote Pakistani culture, 14 respondents said that Turkish dramas promote Hindi culture and 248 respondents said that Turkish dramas promote Western culture in their dramas. Hence prove that Western culture is promoted by Turkish dramas (Figure 19).

\section{What is your perception about outfits in Turkish dramas?: Interpretation}

In this research researcher want to investigate the "effects of Turkish dramas on University students". In this study data collected from three different Universities of Pakistan. Next question about this research is "What is your perception about outfits in Turkish dramas". Firstly data collected from University of Gujrat in which 8 respondents said that outfits in Turkish dramas is shalwar kameez, 43 respondents

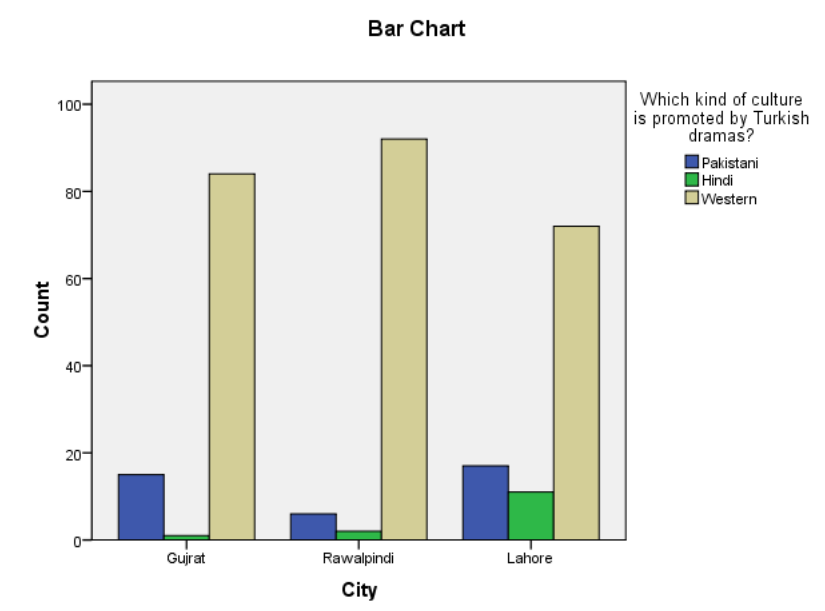

\begin{tabular}{|c|c|c|c|c|c|}
\hline \multicolumn{5}{|c|}{ Which kind of culture is promoted by Turkish dramas? } \\
\hline \multirow{2}{*}{ City } & Pakistani & Hindi & Western & \\
\cline { 2 - 6 } & Gujrat & 15 & 1 & 84 & 100 \\
\cline { 2 - 6 } & Rawalpindi & 6 & 2 & 92 & 100 \\
\cline { 2 - 6 } & Lahore & 17 & 11 & 72 & 100 \\
\hline \multirow{2}{*}{ Total } & 38 & 14 & 248 & 300 \\
\hline
\end{tabular}

Figure 19: Which kind of culture is promoted by Turkish dramas? 
said that outfits in Turkish dramas is jeans and shirts, 9 respondents said that outfits in Turkish dramas is using veil and 40 respondents said that outfits in Turkish dramas is using miniskirts. Secondly data collected from Arid Agriculture University Rawalpindi in which 13 respondents said that outfits in Turkish dramas is using Shalwar kameez, 31 respondents said that outfits in Turkish dramas is using jeans and shirts, 9 respondents said that outfits in Turkish dramas is using veil and 47 respondents said that outfits in Turkish dramas is wearing miniskirts. Thirdly data collected from Punjab University of Lahore in which 18 respondents said that outfits in Turkish dramas is using Shalwar kameez, 48 respondents said that outfits in Turkish dramas is using jeans and shirts, 3 respondents said that outfits in Turkish dramas is using veil and 31 respondents said that outfits in Turkish dramas is wearing miniskirts. Total 300 respondents in which 39 respondents said that outfits in Turkish dramas is using Shalwar kameez, 122 respondents said that outfits in Turkish dramas is using jeans and shirts, 21 respondents said that outfits in Turkish dramas is using veil and 118 respondents said that outfits in Turkish dramas is wearing miniskirts. Hence it proves that outfits is using in Turkish dramas is jeans and shirts (Figure 20).

\section{How often are University students using private TV channels to watch Turkish dramas?: Interpretation}

In this research researcher want to the "effects of Turkish dramas on University students". In this study researcher collected data from three different Universities of Pakistan. The next question about this study is "How often is University students using private TV channels to watch Turkish dramas". Firstly data collected from University of Gujrat in which 6 respondents said that University students using private TV channels to watch Turkish dramas very frequently, 24 respondents said that University students using private TV channels to watch Turkish dramas frequently, 28 respondents said that University students using private TV channels to watch Turkish dramas somewhat, 21 respondents said that University students using private TV channels to

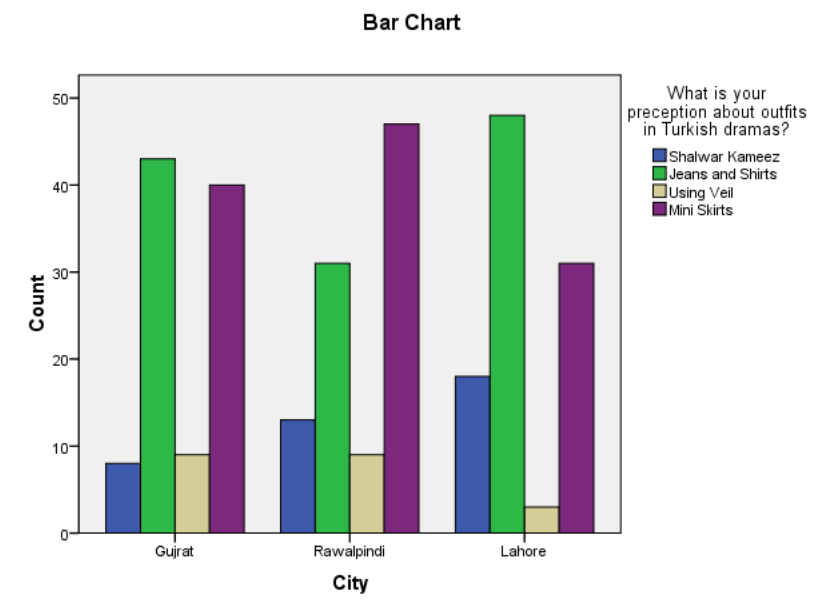

\begin{tabular}{|c|c|c|c|c|c|c|}
\hline \multicolumn{7}{|c|}{ What is your perception about outfits in Turkish dramas? } \\
\hline \multirow{4}{*}{ City } & $\begin{array}{c}\text { Shalwar } \\
\text { kameez }\end{array}$ & $\begin{array}{c}\text { Jeans and } \\
\text { shirts }\end{array}$ & $\begin{array}{c}\text { Using } \\
\text { Veil }\end{array}$ & $\begin{array}{c}\text { Mini } \\
\text { Skirts }\end{array}$ & \\
\cline { 2 - 7 } & Gujrat & 8 & 43 & 9 & 40 & 100 \\
\cline { 2 - 7 } & Rawalpindi & 13 & 31 & 9 & 47 & 100 \\
\cline { 2 - 7 } & Lahore & 18 & 48 & 3 & 31 & 100 \\
\hline \multirow{2}{*}{ Total } & 39 & 122 & 21 & 118 & 300 \\
\hline
\end{tabular}

Figure 20: What is your perception about outfits in Turkish dramas? watch Turkish dramas rarely and 21 respondents said that University students using private TV channels to watch Turkish dramas not at all. Secondly data collected from Arid Agriculture University Rawalpindi in which 11 respondents said that University students using private TV channels to watch Turkish dramas very frequently, 25 respondents said that University students using private TV channels to watch Turkish dramas frequently, 28 respondents said that University students using private TV channels to watch Turkish dramas somewhat, 25 respondents said that University students using private TV channels to watch Turkish dramas rarely and 11 respondents said that University students using private TV channels to watch Turkish dramas not at all. Thirdly data collected from Punjab University Lahore in which 6 respondents said that University students using private TV channels to watch Turkish dramas very frequently, 31 respondents said that University students using private TV channels to watch Turkish dramas frequently, 34 respondents said that University students using private TV channels to watch Turkish dramas somewhat, 16 respondents said that University students using private TV channels to watch Turkish dramas rarely and 13 respondents said that University students using private TV channels to watch Turkish dramas not at all. Total 300 respondents in which 23 respondents said that University students using private TV channels to watch Turkish dramas very frequently, 80 respondents said that University students using private TV channels to watch Turkish dramas frequently, 90 respondents said that University students using private TV channels to watch Turkish dramas somewhat, 62 respondents said that University students using private TV channels to watch Turkish dramas rarely and 45 respondents said that University students using private TV channels to watch Turkish dramas not at all. Hence it proves that University students somewhat using private TV channels (Figure 21).

\section{Bar Chart}

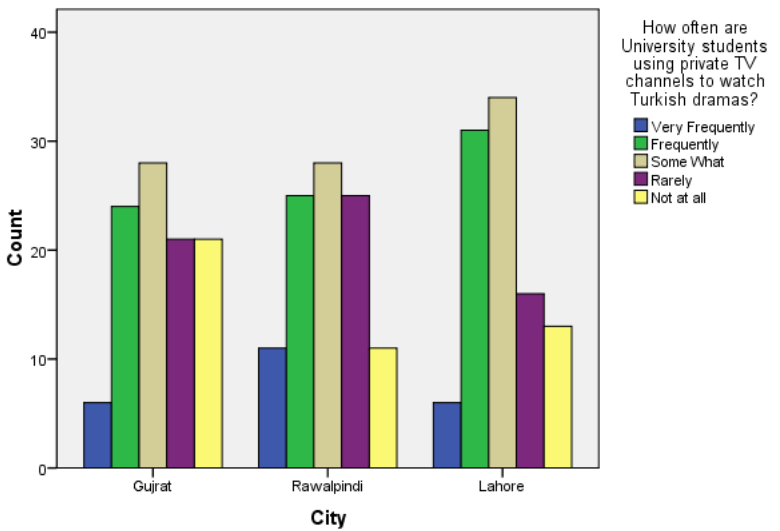

How often are University students using private TV channels to watch
\begin{tabular}{|c|c|c|c|c|c|c|c|} 
Turkish dramas? & $\begin{array}{c}\text { Very } \\
\text { frequently }\end{array}$ & Frequently & & Rarely & $\begin{array}{c}\text { Not } \\
\text { at all }\end{array}$ & \\
\hline \multirow{2}{*}{ City } & Gujrat & 6 & 24 & 28 & 21 & 21 & 100 \\
\cline { 2 - 9 } & Rawalpindi & 11 & 25 & 28 & 25 & 11 & 100 \\
\hline & Lahore & 6 & 31 & 34 & 16 & 13 & 100 \\
\hline & Total & 23 & 80 & 90 & 62 & 45 & 300 \\
\hline
\end{tabular}

Figure 21: How often are University students using private TV channels to watch Turkish dramas? 


\section{Turkish dramas are reshaping our society's concept about marriage and divorce: Interpretation}

In this research researcher want to know the "effects of Turkish dramas on University students".

The next question about this research is "Turkish dramas are reshaping our society's concept about marriage and divorce". Firstly data collected from University of Gujrat in which 11 respondents strongly agree that Turkish dramas are reshaping our society's concept about marriage and divorce, 38 respondents are agree that Turkish dramas are reshaping our society's concept about marriage and divorce, 24 respondents are response neutrally that Turkish dramas are reshaping our society's concept about marriage and divorce, 21 respondents are disagree that Turkish dramas are reshaping our society's concept about marriage and divorce, 6 respondents are strongly disagree that Turkish dramas are reshaping our society's concept about marriage and divorce. Secondly data collected from Arid Agriculture University Rawalpindi in which 11 respondents are strongly agree that Turkish dramas are reshaping our society's concept about marriage and divorce, 37 respondents are agree that Turkish dramas are reshaping our society's concept about marriage and divorce, 29 respondents are given answer neutrally that Turkish dramas are reshaping our society's concept about marriage and divorce, 21 respondents are disagree that Turkish dramas are reshaping our society's concept about marriage and divorce, 2 respondents are strongly disagree that Turkish dramas are reshaping our society's concept about marriage and divorce. Thirdly data collected from Punjab University Lahore in which 12 respondents are strongly agree that Turkish dramas are reshaping our society's concept about marriage and divorce, 40 respondents are agree that Turkish dramas are reshaping our society's concept about marriage and divorce, 14 respondents are neutral that Turkish dramas are reshaping our society's concept about marriage and divorce, 33 respondents are disagree that Turkish dramas are reshaping our society's concept about marriage and divorce, 1 respondents strongly disagree that Turkish dramas are reshaping our society's concept about marriage and divorce, total 300 respondents in which 34 respondents are strongly agree that Turkish dramas are reshaping our society's concept about marriage and divorce, 115 respondents are agree that Turkish dramas are reshaping our society's concept about marriage and divorce, 67 respondents are neutral that Turkish dramas are reshaping our society's concept about marriage and divorce, 75 are disagree that Turkish dramas are reshaping our society's concept about marriage and divorce and 9 respondents are strongly disagree that Turkish dramas are reshaping our society's concept about marriage and divorce. Now it does prove that Turkish dramas are reshaping our society's concept about marriage and divorce (Figure 22).

\section{Turkish dramas are presenting real representation of Islam: Interpretation}

In this research researcher want to know the "effects of Turkish dramas on University students". The next question about this research is "Turkish dramas are presenting real representation of Islam". Firstly data collected from University of Gujrat in which 2 respondents strongly agree that Turkish dramas are presenting real representation of Islam, 9 respondents are agree that Turkish dramas are presenting real representation of Islam, 19 respondents are response neutrally that Turkish dramas are presenting real representation of Islam, 18 respondents are disagree that Turkish dramas are presenting real representation of Islam, 52 respondents are strongly disagree that Turkish dramas are presenting real representation of Islam. Secondly data collected from Arid Agriculture University Rawalpindi in which 2 respondents are strongly agree that Turkish dramas are presenting real representation of Islam, 11 respondents are agree that Turkish dramas

\section{Bar Chart}

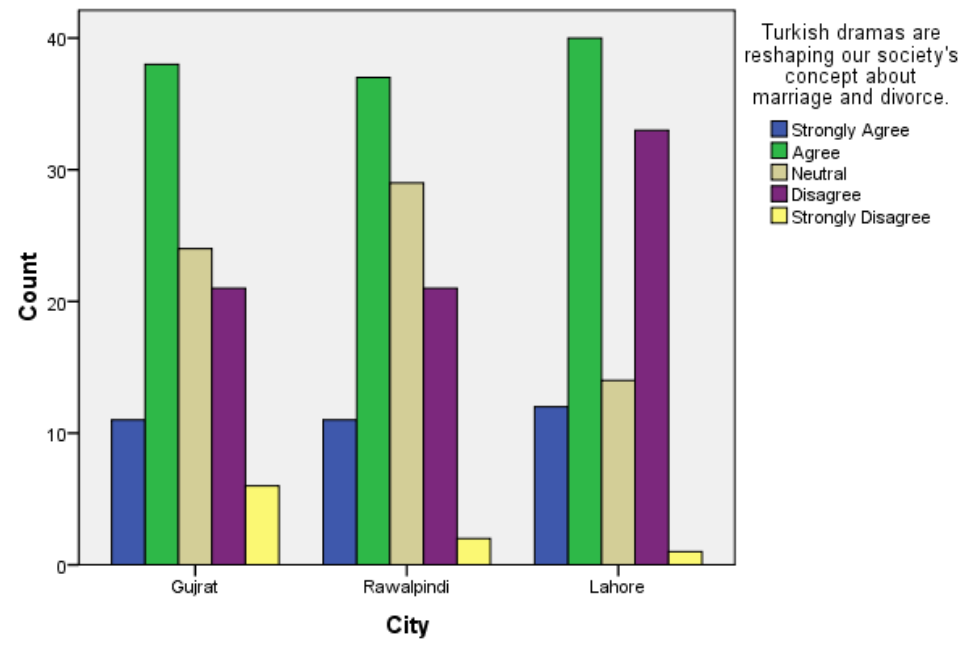

Turkish dramas are reshaping our society's concept about marriage and divorce.

\begin{tabular}{|c|c|c|c|c|c|c|c|}
\hline \multicolumn{8}{|c|}{ Turkish dramas are reshaping our society's concept about marriage and divorce. } \\
\hline & & Strongly agree & Agree & Neutral & Disagree & Strongly disagree & \\
\hline \multirow[t]{3}{*}{ City } & Gujrat & 11 & 38 & 24 & 21 & 6 & 100 \\
\hline & Rawalpindi & 11 & 37 & 29 & 21 & 2 & 100 \\
\hline & Lahore & 12 & 40 & 14 & 33 & 1 & 100 \\
\hline \multicolumn{2}{|c|}{ Total } & 34 & 115 & 67 & 75 & 9 & 300 \\
\hline
\end{tabular}

Figure 22: Turkish dramas are reshaping our society's concept about marriage and divorce. 
are presenting real representation of Islam, 19 respondents are given answer neutrally that Turkish dramas are presenting real representation of Islam, 32 respondents are disagree that Turkish dramas are presenting real representation of Islam, 36 respondents are strongly disagree that Turkish dramas are presenting real representation of Islam. Thirdly data collected from Punjab University Lahore in which 13 respondents are strongly agree that Turkish dramas are presenting real representation of Islam, 13 respondents are agree that Turkish dramas are presenting real representation of Islam, 13 respondents are neutral that Turkish dramas are presenting real representation of Islam, 40 respondents are disagree that Turkish dramas are presenting real representation of Islam, 21 respondents strongly disagree that Turkish dramas are presenting real representation of Islam, total 300 respondents in which 17 respondents are strongly agree that Turkish dramas are presenting real representation of Islam and, 33 respondents are agree that Turkish dramas are presenting real representation of Islam, 51 respondents are neutral that Turkish dramas are presenting real representation of Islam, 90 are disagree that Turkish dramas are presenting real representation of Islam and 109 respondents are strongly disagree that Turkish dramas are presenting real representation of Islam. Hence prove that Turkish dramas are not presenting the real representation of Islam (Figure 23).

\section{University students are acting like models of Turkish dramas: Interpretation}

In this research researcher want to know the "effects of Turkish dramas on University students". The next question about this research is "University students are acting like models of Turkish dramas". Firstly data collected from University of Gujrat in which 10 respondents strongly agree that University students are acting like models of Turkish dramas, 12 respondents are agree that University students are acting like models of Turkish dramas, 33 respondents are response neutrally that University students are acting like models of Turkish dramas,
33 respondents are disagree that University students are acting like models of Turkish dramas, 12 respondents are strongly disagree that University students are acting like models of Turkish dramas. Secondly data collected from Arid Agriculture University Rawalpindi in which 7 respondents are strongly agree that University students are acting like models of Turkish dramas, 19 respondents are agree that University students are acting like models of Turkish dramas, 38 respondents are given answer neutrally that University students are acting like models of Turkish dramas, 31 respondents are disagree that University students are acting like models of Turkish dramas, 5 respondents are strongly disagree that University students are acting like models of Turkish dramas. Thirdly data collected from Punjab University Lahore in which 22 respondents are strongly agree University students are acting like models of Turkish dramas, 37 respondents are agree that University students are acting like models of Turkish dramas, 13 respondents are neutral that University students are acting like models of Turkish dramas, 19 respondents are disagree that University students are acting like models of Turkish dramas, 9 respondents strongly disagree that University students are acting like models of Turkish dramas. Total 300 respondents in which 39 respondents are strongly agree that University students are acting like models of Turkish dramas, 68 respondents are agree that University students are acting like models of Turkish dramas, 84 respondents are neutral that University students are acting like models of Turkish dramas, 83 are disagree that University students are acting like models of Turkish dramas and 26 respondents are strongly disagree that University students are acting like models of Turkish dramas. Hence prove that University students are acting like models of Turkish dramas (Figure 24).

\section{University students are influenced by the styles of Turkish drama models: Interpretation}

In this research researcher want to know the "effects of Turkish

\section{Bar Chart}

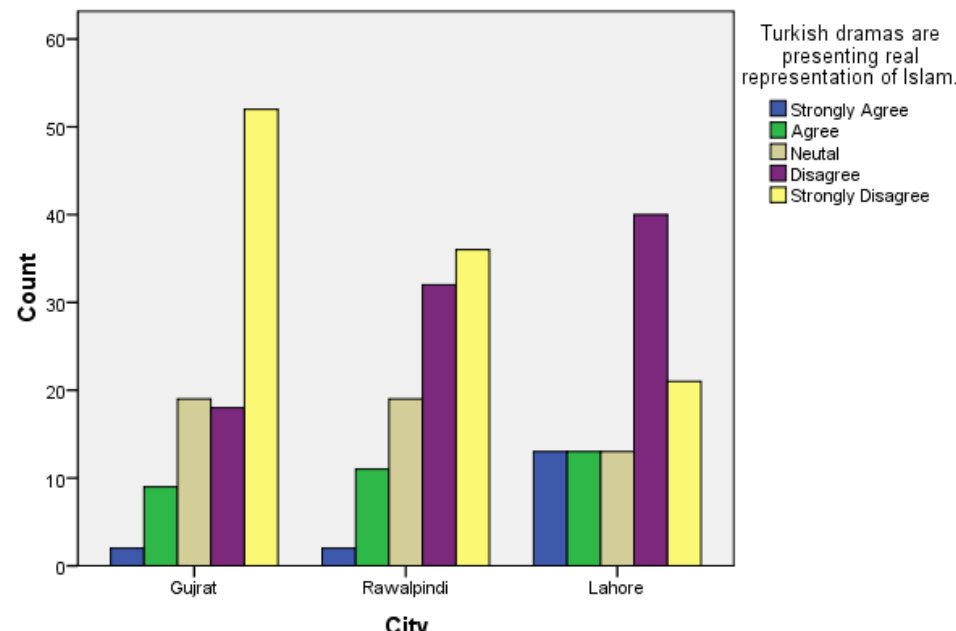

City

\begin{tabular}{|c|c|c|c|c|c|c|c|}
\hline \multicolumn{8}{|c|}{ Turkish dramas are presenting real representation of Islam. Cross tabulation } \\
\hline & & Strongly agree & Agree & Neutral & Disagree & Strongly disagree & Total \\
\hline \multirow[t]{3}{*}{ City } & Gujrat & 2 & 9 & 19 & 18 & 52 & 100 \\
\hline & Rawalpindi & 2 & 11 & 19 & 32 & 36 & 100 \\
\hline & Lahore & 13 & 13 & 13 & 40 & 21 & 100 \\
\hline \multicolumn{2}{|c|}{ Total } & 17 & 33 & 51 & 90 & 109 & 300 \\
\hline
\end{tabular}

Figure 23: Turkish dramas are presenting real representation of Islam. 


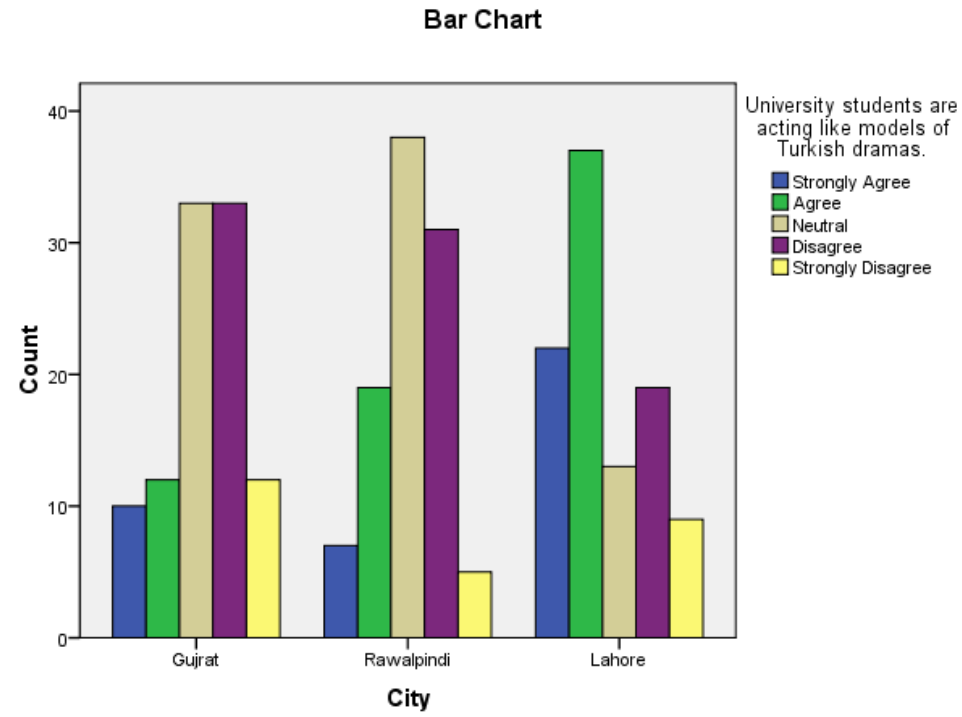

\begin{tabular}{|c|c|c|c|c|c|c|c|}
\hline \multicolumn{8}{|c|}{ University students are acting like models of Turkish dramas. Cross tabulation } \\
\hline & & Strongly agree & Agree & Neutral & Disagree & Strongly disagree & Total \\
\hline \multirow[t]{3}{*}{ City } & Gujrat & 10 & 12 & 33 & 33 & 12 & 100 \\
\hline & Rawalpindi & 7 & 19 & 38 & 31 & 5 & 100 \\
\hline & Lahore & 22 & 37 & 13 & 19 & 9 & 100 \\
\hline \multicolumn{2}{|c|}{ Total } & 39 & 68 & 84 & 83 & 26 & 300 \\
\hline
\end{tabular}

Figure 24: University students are acting like models of Turkish dramas.

dramas on University students". The next question about this research is "University students are influenced by the styles of Turkish drama models". Firstly data collected from University of Gujrat in which 10 respondents strongly agree that University students are influenced by the styles of Turkish drama models, 32 respondents are agree that University students are influenced by the styles of Turkish drama models, 24 respondents are response neutrally that University students are influenced by the styles of Turkish drama models, 17 respondents are disagree that University students are influenced by the styles of Turkish drama models, 17 respondents are strongly disagree that University students are influenced by the styles of Turkish drama models. Secondly data collected from Arid Agriculture University Rawalpindi in which 8 respondents are strongly agree that University students are influenced by the styles of Turkish drama models, 26 respondents are agree that University students are influenced by the styles of Turkish drama models, 22 respondents are given answer neutrally that University students are influenced by the styles of Turkish drama models, 36 respondents are disagree that University students are influenced by the styles of Turkish drama models, 8 respondents are strongly disagree that University students are influenced by the styles of Turkish drama models. Thirdly data collected from Punjab University Lahore in which 25 respondents are strongly agree University students are influenced by the styles of Turkish drama models, 50 respondents are agree that University students are influenced by the styles of Turkish drama models, 8 respondents are neutral that University students are influenced by the styles of Turkish drama models, 16 respondents are disagree that University students are influenced by the styles of Turkish drama models and only 1 respondent strongly disagree that University students are influenced by the styles of Turkish drama models. Total 300 respondents in which 43 respondents are strongly agree that University students are influenced by the styles of Turkish drama models, 108 respondents are agree that University students are influenced by the styles of Turkish drama models, 54 respondents are neutral that University students are influenced by the styles of Turkish drama models, 69 are disagree that University students are influenced by the styles of Turkish drama models and 26 respondents are strongly disagree that University students are influenced by the styles of Turkish drama models. Hence prove that University students are influenced by the styles of Turkish drama models (Figure 25).

\section{University students are trying to adopt the styles of models of Turkish dramas: Interpretation}

In this research researcher want to know the "effects of Turkish dramas on University students". The next question about this research is "University students are trying to adopt the styles of models of Turkish dramas". Firstly data collected from University of Gujrat in which 9 respondents strongly agree that University students are trying to adopt the styles of models of Turkish dramas, 22 respondents are agree that University students are trying to adopt the styles of models of Turkish dramas, 27 respondents are response neutrally that University students are trying to adopt the styles of models of Turkish dramas, 25 respondents are disagree that University students are trying to adopt the styles of models of Turkish dramas, 17 respondents are strongly disagree that University students are trying to adopt the styles of models of Turkish dramas. Secondly data collected from Arid Agriculture University Rawalpindi in which 8 respondents are strongly agree that University students are trying to adopt the styles of models of Turkish dramas, 23 respondents are agree that University students are trying to adopt the styles of models of Turkish dramas, 32 respondents are given answer neutrally that University students are trying to adopt the styles of models of Turkish dramas, 31 respondents are disagree that University students are trying to adopt the styles of models of Turkish dramas, 6 respondents are strongly disagree that University students are trying to adopt the styles of models of Turkish dramas. Thirdly 


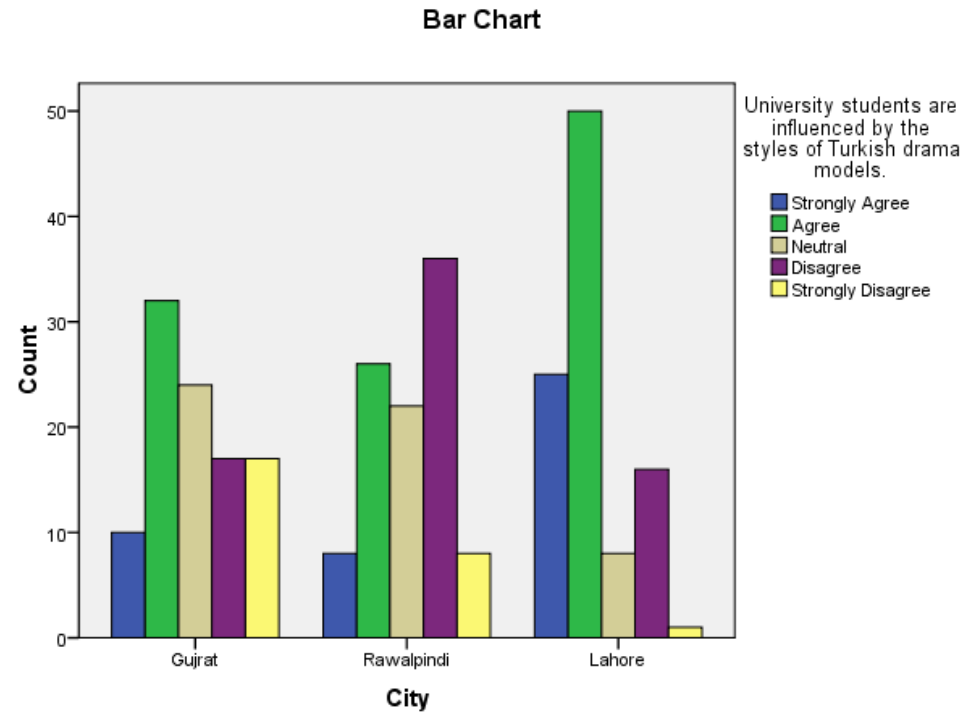

\begin{tabular}{|c|c|c|c|c|c|c|c|}
\hline \multicolumn{8}{|c|}{ University students are influenced by the styles of Turkish drama models. Cross tabulation } \\
\hline & & Strongly agree & Agree & Neutral & Disagree & Strongly disagree & Total \\
\hline \multirow[t]{3}{*}{ City } & Gujrat & 10 & 32 & 24 & 17 & 17 & 100 \\
\hline & Rawalpindi & 8 & 26 & 22 & 36 & 8 & 100 \\
\hline & Lahore & 25 & 50 & 8 & 16 & 1 & 100 \\
\hline \multicolumn{2}{|c|}{ Total } & 43 & 108 & 54 & 69 & 26 & 300 \\
\hline
\end{tabular}

Figure 25: University students are influenced by the styles of Turkish drama models.

data collected from Punjab University Lahore in which 20 respondents are strongly agree University students are trying to adopt the styles of models of Turkish dramas, 41 respondents are agree that University students are trying to adopt the styles of models of Turkish dramas, 13 respondents are neutral that University students are trying to adopt the styles of models of Turkish dramas, 23 respondents are disagree that University students are trying to adopt the styles of models of Turkish dramas and 3 respondents strongly disagree that University students are trying to adopt the styles of models of Turkish dramas. Total 300 respondents in which 37 respondents are strongly agree that University students are trying to adopt the styles of models of Turkish dramas, 86 respondents are agree that University students are trying to adopt the styles of models of Turkish dramas, 72 respondents are neutral that University students are trying to adopt the styles of models of Turkish dramas, 79 are disagree that University students are trying to adopt the styles of models of Turkish dramas and 26 respondents are strongly disagree that University students are trying to adopt the styles of models of Turkish dramas. Hence prove that University students are trying to adopt the styles of models of Turkish dramas (Figure 26).

\section{Turkish dramas are making women more independent: Interpretation}

In this research researcher want to know the "effects of Turkish dramas on University students". The next question about this research is "Turkish dramas are making women more independent". Firstly data collected from University of Gujrat in which 18 respondents strongly agree that Turkish dramas are making women more independent, 29 respondents are agree that Turkish dramas are making women more independent, 21 respondents are response neutrally that Turkish dramas are making women more independent, 12 respondents are disagree that Turkish dramas are making women more independent, 20 respondents are strongly disagree that Turkish dramas are making women more independent. Secondly data collected from Arid Agriculture University Rawalpindi in which 16 respondents are strongly agree that Turkish dramas are making women more independent, 39 respondents are agree that Turkish dramas are making women more independent, 28 respondents are given answer neutrally that Turkish dramas are making women more independent, 12 respondents are disagree that Turkish dramas are making women more independent, 5 respondents are strongly disagree that Turkish dramas are making women more independent. Thirdly data collected from Punjab University Lahore in which 34 respondents are strongly agree Turkish dramas are making women more independent, 31 respondents are agree that Turkish dramas are making women more independent, 9 respondents are neutral that Turkish dramas are making women more independent, 18 respondents are disagree that Turkish dramas are making women more independent and 8 respondents strongly disagree that Turkish dramas are making women more independent. Total 300 respondents in which 68 respondents are strongly agree that Turkish dramas are making women more independent, 99 respondents are agree that Turkish dramas are making women more independent, 58 respondents are neutral that Turkish dramas are making women more independent, 42 are disagree that Turkish dramas are making women more independent and 33 respondents are strongly disagree that Turkish dramas are making women more independent. Hence prove that Turkish dramas are making women more independent (Figure 27).

\section{Hypothesis Testing}

The first hypothesis is "Turkish dramas are affecting the Islamic values among University students", the second hypothesis is "University students are influenced by the styles of Turkish drama models", the third hypothesis is "University students are trying to adopt the styles of models of Turkish dramas" (Table 1). 


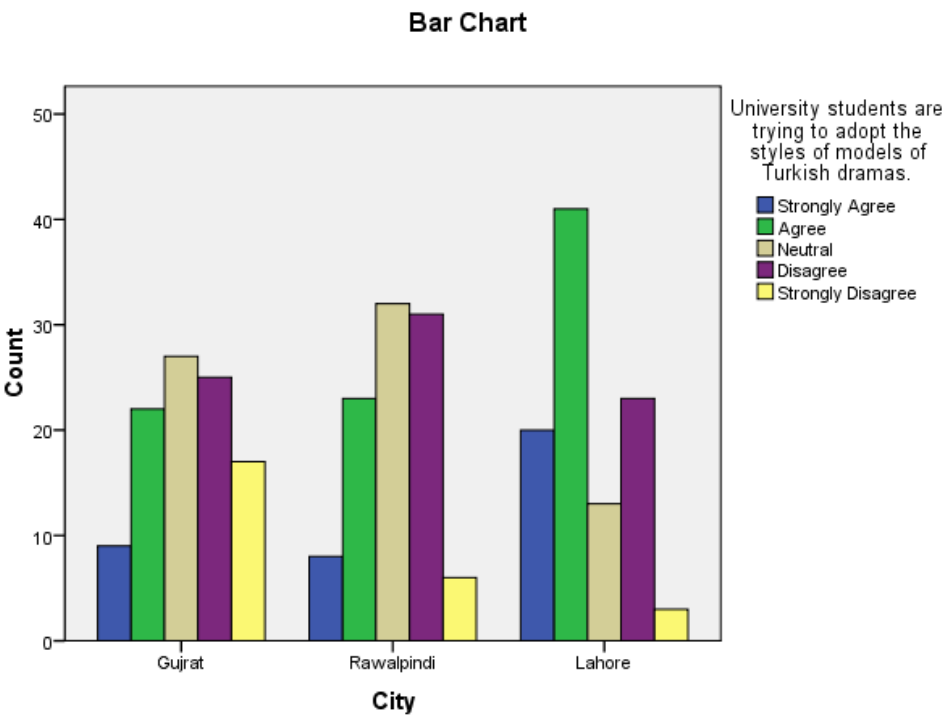

\begin{tabular}{|c|c|c|c|c|c|c|c|}
\hline \multicolumn{8}{|c|}{ University students are trying to adopt the styles of models of Turkish dramas. } \\
\hline & & Strongly agree & Agree & Neutral & Disagree & Strongly disagree & Total \\
\hline \multirow[t]{3}{*}{ City } & Gujrat & 9 & 22 & 27 & 25 & 17 & 100 \\
\hline & Rawalpindi & 8 & 23 & 32 & 31 & 6 & 100 \\
\hline & Lahore & 20 & 41 & 13 & 23 & 3 & 100 \\
\hline \multicolumn{2}{|c|}{ Total } & 37 & 86 & 72 & 79 & 26 & 300 \\
\hline
\end{tabular}

Figure 26: University students are trying to adopt the styles of models of Turkish dramas.

\section{Bar Chart}

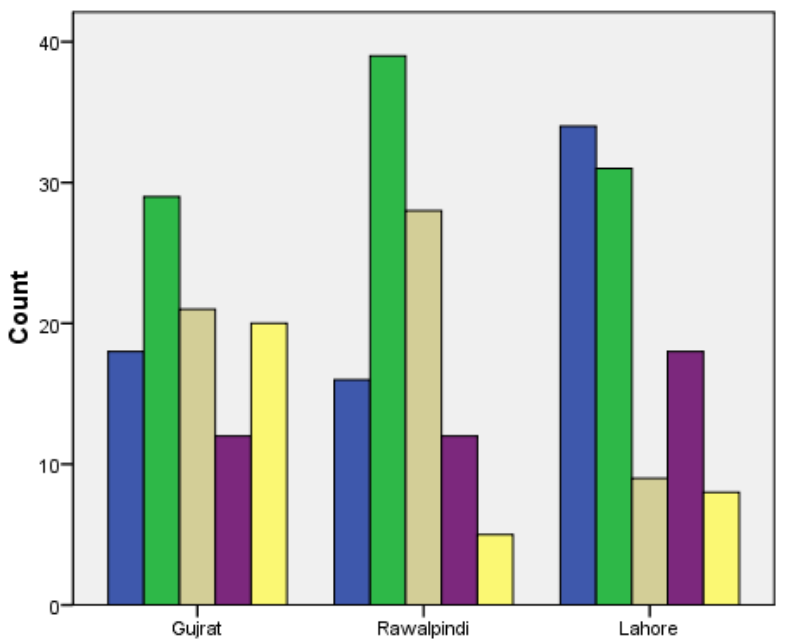

City
Turkish dramas are making women more independent.

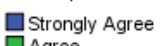

$\square$ Agree

$\square$ Neutral

Strongly Disagree

\begin{tabular}{|c|c|c|c|c|c|c|c|}
\hline \multicolumn{8}{|c|}{ Turkish dramas are making women more independent. Cross tabulation } \\
\hline & & Strongly agree & Agree & Neutral & Disagree & Strongly disagree & Total \\
\hline \multirow[t]{3}{*}{ City } & Gujrat & 18 & 29 & 21 & 12 & 20 & 100 \\
\hline & Rawalpindi & 16 & 39 & 28 & 12 & 5 & 100 \\
\hline & Lahore & 34 & 31 & 9 & 18 & 8 & 100 \\
\hline \multicolumn{2}{|c|}{ Total } & 68 & 99 & 58 & 42 & 33 & 300 \\
\hline
\end{tabular}

Figure 27: Turkish dramas are making women more independent. 


\begin{tabular}{|c|c|c|c|c|c|}
\hline \multicolumn{6}{|c|}{ Correlations } \\
\hline & & City & $\begin{array}{l}\text { Do you think Turkish } \\
\text { dramas affect your } \\
\text { Islamic values? }\end{array}$ & $\begin{array}{l}\text { University students } \\
\text { are influenced by } \\
\text { the styles of Turkish } \\
\text { drama models. }\end{array}$ & $\begin{array}{l}\text { University students } \\
\text { are trying to adopt the } \\
\text { styles of models of } \\
\text { Turkish dramas. }\end{array}$ \\
\hline \multirow[t]{3}{*}{ City } & Pearson Correlation & 1 & .024 & $-.275^{\star *}$ & $-.247^{\star *}$ \\
\hline & Sig. (2-tailed) & & .673 & .000 & .000 \\
\hline & $\mathrm{N}$ & 300 & 300 & 300 & 300 \\
\hline \multirow{3}{*}{$\begin{array}{l}\text { Do you think Turkish dramas affect your } \\
\text { Islamic values? }\end{array}$} & Pearson Correlation & 0.024 & 1 & .078 & .093 \\
\hline & Sig. (2-tailed) & .673 & & .180 & .110 \\
\hline & $\mathrm{N}$ & 300 & 300 & 300 & 300 \\
\hline \multirow{3}{*}{$\begin{array}{l}\text { University students are influenced by the } \\
\text { styles of Turkish drama models. }\end{array}$} & Pearson Correlation & $-.275^{\star \star}$ & .078 & 1 & $.702^{\star \star}$ \\
\hline & Sig. (2-tailed) & .000 & .180 & & .000 \\
\hline & $\mathrm{N}$ & 300 & 300 & 300 & 300 \\
\hline \multirow{3}{*}{$\begin{array}{l}\text { University students are trying to adopt } \\
\text { the styles of models of Turkish dramas. }\end{array}$} & Pearson Correlation & $-.247^{* *}$ & .093 & $.702^{* *}$ & 1 \\
\hline & Sig. (2-tailed) & .000 & .110 & .000 & \\
\hline & $\mathrm{N}$ & 300 & 300 & 300 & 300 \\
\hline \multicolumn{3}{|c|}{ **. Correlation is significant at the 0.01 level (2-tailed). } & & & \\
\hline
\end{tabular}

Table 1: Correlations.

\section{First}

The first hypothesis is "Turkish dramas are affecting the Islamic values among University students". Correlation method was used, correlate the hypothesis with city. Data collected from University student's total 300 respondents were selected and on the bases of data collection this hypothesis proves that Turkish dramas are not affecting the Islamic values among University students. This hypothesis was rejected on this research data collection based.

\section{Second}

The second hypothesis is "University students are influenced by the styles of Turkish drama models". Correlation hypothesis testing method was use for this research. This is city vise analysis and that's way hypothesis correlate with the city. Data collected from University student's total 300 respondents were selected and on the bases of data collection this hypothesis proves that University students are influenced by the styles of Turkish dramas models. This hypothesis was approved on this research data collection based.

\section{Third}

The third hypothesis is "University students are trying to adopt the styles of models of Turkish dramas". Correlation hypothesis testing method was use for this research. This is city vise analysis and that's way hypothesis correlate with the city. Data collected from University student's total 300 respondents were selected and on the bases of data collection this hypothesis proves that University students are trying to adopt the styles of models of Turkish dramas. This hypothesis was approved on this research data collection based. And this hypothesis is significant correlation study.

\section{Summary and Discussion}

In this research topic was selected the "EFFECTS OF TURKISH DRAMAS ON UNIVERSITY STUDENTS". For this research researcher select three different Universities of Pakistan like University of Gujrat, Arid Agriculture University Rawalpindi and Punjab University Lahore. The purpose of this study to choose the University students is that when change came in any society especially the youngster are affected to this change. That's way researcher chooses the University students for this research because they are the youngest generation of the country. To collect data from the University student's researcher develops a questionnaire which depends upon the twenty five questions about this research. And also age and city two more factors are add in this research. Firstly select age factor which divided into two categories like eighteen to twenty one and twenty two to twenty five total 300 respondents in which 198 respondents fall in first category and 102 respondents fall in second category. Next question is about University three different Universities total 300 respondents and 100 respondents select every University of Pakistan. Next question is about watching TV, data collected from those respondents who must watch TV that's way all 300 respondents give response yes they all are watching TV. Next question is about watching TV dramas for this purpose data collected only from those respondents who are watching TV dramas that way all 300 respondents said that they are watching TV dramas. Data collected from only those respondents who are watching Turkish dramas. And for that reason all 300 respondents watch Turkish dramas. 68 respondents said that Turkish dramas present Islamic values and 232 respondents said that Turkish dramas do not present Islamic values. Hence it proves that Turkish dramas do not present Islamic values. 49 respondents said that they are following the styles of Turkish drama models and 251 respondents said that that they do not follow the styles of Turkish drama models. Hence it proves that they do not follow the styles of Turkish drama models. 152 respondents said that Turkish dramas are affecting Islamic values and 148 respondents said that Turkish dramas do not affecting Islamic values. Hence it proves that Turkish dramas affect Islamic values. 111 respondents said that Turkish dramas are best source of entertainment and 189 respondents said that Turkish dramas are not best source of entertainment. Hence it proves that Turkish dramas are not best source of entertainment. 172 respondents said that Turkish dramas are changing dressing style of University students and 128 respondents said that Turkish dramas do not changing dressing style of University students. Hence it proves that Turkish dramas are changing dressing style of University students. 132 respondents said that Pakistani channels are promoting Turkish dramas and 68 respondents said that Pakistani channels are promoting Turkish dramas. Hence it proves that Pakistani channels are promoting Turkish dramas. 236 respondents said that Turkish dramas are influenced by Western culture and 64 respondents said that Turkish dramas are not influenced by Western culture. Now prove that Turkish dramas are influenced by Western culture. 201 respondents said that Turkish dramas promote liberty among Pakistani women and 99 respondents said that Turkish dramas 
are not promoting liberty among Pakistani women. Hence prove that Turkish dramas promote liberty among Pakistani women. 78 respondents said that Turkish dramas are presenting portrayal of women by media in accordance with Islam and 222 respondents said that Turkish dramas are not presenting portrayal of women by media in Islam. Hence prove that Turkish dramas are not presenting portrayal of women by media in accordance with Islam. 61 respondents give response that life style in Turkish dramas is according to Islam and 239 give response that life style in Turkish dramas is not according to Islam. Hence prove that life style in Turkish dramas is not according to Islam. 53 respondents give response that dress code in Turkish dramas is according to Islam and 247 give response that dress code in Turkish dramas is not according to Islam. Hence prove that the dress code in Turkish dramas is not according to Islam. 86 respondents said that they are watching TV 1 hour, 97 said that they are watching TV 2 hours, 81 respondents said that they are watching TV 3 hours, 16 respondents said that they are watching TV 4 hours, and 20 respondents said that they are watching TV more than 4 hours. It is prove that mostly respondents watch TV 2 hours in a day. 212 respondents said that they are watching Turkish dramas 1 hour, 66 said that they are watching Turkish dramas 2 hours, 11 respondents said that they are watching Turkish dramas 3 hours, 3 respondents said that they are watching Turkish dramas 4 hours, and 8 respondents said that they are watching Turkish dramas more than 4 hours. Now prove that mostly respondents watch Turkish dramas one hour per day. 38 respondents said that Turkish dramas promote Pakistani culture, 14 respondents said that Turkish dramas promote Hindi culture and 248 respondents said that Turkish dramas promote Western culture in their dramas. Hence prove that Western culture is promoted by Turkish dramas. 23 respondents said that University students using private TV channels to watch Turkish dramas very frequently, 80 respondents said that University students using private TV channels to watch Turkish dramas frequently, 90 respondents said that University students using private TV channels to watch Turkish dramas somewhat, 62 respondents said that University students using private TV channels to watch Turkish dramas rarely and 45 respondents said that University students using private TV channels to watch Turkish dramas not at all. Hence it proves that University students somewhat using private TV channels. 34 respondents are strongly agree that Turkish dramas are reshaping our society's concept about marriage and divorce, 115 respondents are agree that Turkish dramas are reshaping our society's concept about marriage and divorce, 67 respondents are neutral that Turkish dramas are reshaping our society's concept about marriage and divorce, 75 are disagree that Turkish dramas are reshaping our society's concept about marriage and divorce and 9 respondents are strongly disagree that Turkish dramas are reshaping our society's concept about marriage and divorce. Now it does prove that Turkish dramas are reshaping our society's concept about marriage and divorce. 17 respondents are strongly agree that Turkish dramas are presenting real representation of Islam and, 33 respondents are agree that Turkish dramas are presenting real representation of Islam, 51 respondents are neutral that Turkish dramas are presenting real representation of Islam, 90 are disagree that Turkish dramas are presenting real representation of Islam and 109 respondents are strongly disagree that Turkish dramas are presenting real representation of Islam. Hence prove that Turkish dramas are not presenting the real representation of Islam. 39 respondents are strongly agree that University students are acting like models of Turkish dramas, 68 respondents are agree that University students are acting like models of Turkish dramas, 84 respondents are neutral that University students are acting like models of Turkish dramas, 83 are disagree that University students are acting like models of Turkish dramas and 26 respondents are strongly disagree that University students are acting like models of Turkish dramas. Hence prove that University students are acting like models of Turkish dramas. 43 respondents are strongly agree that University students are influenced by the styles of Turkish drama models, 108 respondents are agree that University students are influenced by the styles of Turkish drama models, 54 respondents are neutral that University students are influenced by the styles of Turkish drama models, 69 are disagree that University students are influenced by the styles of Turkish drama models and 26 respondents are strongly disagree that University students are influenced by the styles of Turkish drama models. Hence prove that University students are influenced by the styles of Turkish drama models. 37 respondents are strongly agree that University students are trying to adopt the styles of models of Turkish dramas, 86 respondents are agree that University students are trying to adopt the styles of models of Turkish dramas, 72 respondents are neutral that University students are trying to adopt the styles of models of Turkish dramas, 79 are disagree that University students are trying to adopt the styles of models of Turkish dramas and 26 respondents are strongly disagree that University students are trying to adopt the styles of models of Turkish dramas. Hence prove that University students are trying to adopt the styles of models of Turkish dramas. 68 respondents are strongly agree that Turkish dramas are making women more independent, 99 respondents are agree that Turkish dramas are making women more independent, 58 respondents are neutral that Turkish dramas are making women more independent, 42 are disagree that Turkish dramas are making women more independent and 33 respondents are strongly disagree that Turkish dramas are making women more independent. Hence prove that Turkish dramas are making women more independent.

Results of this research prove that effects of Turkish dramas are very strong on University students. In Pakistani TV channels Turkish dramas are likely watched by the audience. University students are influenced by the styles of Turkish dramas models and also they are adopting their life style and dressing styles. But they do not affect the Islamic values. One more thing is that they are promote liberty among Pakistani women they know how to make ourselves independent now a days.

\section{Conclusion}

This study is about the effects of Turkish dramas on University students. From which three Pakistani Universities were selected to get data i.e., University of Gujrat, Arid Agriculture University Rawalpindi and Punjab University Lahore. In this research prove that effects of Turkish dramas are very strong on University students. In Pakistani TV channels Turkish dramas are likely watched by the audience. University students are influenced by the styles of Turkish dramas models and also they are adopting their life style and dressing styles. But they do not affect the Islamic values. One more thing is that they are promote liberty among Pakistani women they know how to make ourselves independent now a days. Three hypothesis were develop in this research like University students are influenced by the styles of Turkish dramas models and this hypothesis is accepted through this research mostly respondents said that they are influenced by the styles of Turkish dramas models. Next hypothesis is University are trying to adopt the styles of Turkish dramas models and mostly respondents said that they like the styles of Turkish dramas models that's way they are trying to adopt their styles. Last hypothesis is Turkish dramas are affecting the Islamic values because Turkey represent the Islam religion but they don't show Islam in their dramas and this hypothesis is rejected because they don't affect the Islamic values among University students. 
Citation: Iqbal M (2018) Effects of Turkish Dramas on University Students: A Survey of Pakistani Universities. J Mass Communicat Journalism 8: 394. doi: 10.4172/2165-7912.1000394

Page 22 of 22

\section{Suggestions and Recommendations}

$>$ Above study result suggested that Pakistani TV channels should promote Pakistani dramas and culture.

$>$ It is suggested that Pakistani TV channels should show Islamic values in their dramas.

$>$ Pakistani channels should promote only those dramas which according only Islamic religion.

> Pakistani channels publish only those content which presenting portrayal of women by accordance with Islam.

$>$ It is recommended that TV dramas should highlight the women issues and problems.

$>$ It is also suggested that PEMRA should allow channels to publish only those content which is not against our culture and religion.

$>$ Media should portray simplicity and must follow the limits of our culture.

$>$ Media should publish only those contents which have positive effects on youngsters.

$>$ Unethical and against Islam contents should be banned by the government totally.

\section{References}

1. Alankuş S, Yanardağoğlu E (2016) Vacillation in Turkey's Popular Global TV Exports: Toward a More Complex Understanding of Distribution. International Journal of Communication 10: 3615-3631.

2. Yesil B (2015) Transnationalization of Turkish dramas: Exploring the convergence of local and global market imperatives. Global Media and Communication 11: 43-60.

3. Zafar A, Arafat Y, Sial NR (2017) Effects of Turkish Soap Operas On The Female Youth of Pakistan. The Women-Annual Research Journal of Gender Studies 9: 92-107.

4. Khan FW (2011) Mirrors of Governance: The Mighty Turkish Diadem'and English Drama. Journal of European Studies 26-27: 139.
5. Kaynak MS (2015) Noor and friends: Turkish culture in the world. In Turkey's Public Diplomacy. Palgrave Macmillan, New York.

6. Kim S, Kim M, Agrusa J, Lee A (2012) Does a food-themed TV drama affect perceptions of national image and intention to visit a country? An empirical study of Korea TV drama. Journal of Travel and Tourism Marketing 29: 313-326.

7. Shabir G, Safdar G, Imran M (2013) Cultural Effects of Urdu Dramas of GEO and HUM TV on women: A Case Study of Bahawalpur, Pakistan. The WomenAnnual Research Journal of Gender Studies.

8. Shahbaz Aslam D, Ali A, Ullah F, Munawar M (2015) Socio-Ethical Impact of Turkish Dramas on Educated Females of Gujranwala-Pakistan.

9. Zia A (2007) Effects of cable television on women in Pakistan: A comparative study of heavy and light viewers in Lahore. Submitted to Lahore College for Women University, Lahore, in fulfillment of the requirements for the degree if Doctor of Philosophy in mass Communication.

10. Ghazanfar S, Zeeshan M, Ullah K, Shehnaz S, Hussain M (2015) Changes In Family Values Due To Information Communication Technologies 1: 385-389.

11. Madni AR, Abdullah M, Hassan A, Nawaz T (2014) Portrayal of fashion by Turkish and Pakistani dramas on major private TV channels and viewers perception. Asian Journal of Empirical Research 4: 95-103.

12. Dubow EF, Huesmann LR, Greenwood D (2007) Media and Youth Socialization: Underlying Processes and Moderators of Effects, pp: 404-430.

13. Biçer R (2011) The Important of the TV on the Religious Understanding of Turkish People. Ejovoc.

14. Cetin KBE (2014) The Politicization of Turkish Television Dramas. International Journal of Communication 8: 22.

15. Khan AY, Razi A, Mirza R, Mazhar S, Amjad A, Shafique U (2013) Impact of mass media in Pakistan on social, ethical, and economic grounds. Int J Eco Res 4: 1-20.

16. Abbasi A, Akhter W, Umar S (2011) Ethical issues in advertising in Pakistan: An Islamic perspective.

17. Rousselin M (2013) Turkish Soap Power: International Perspectives and Domestic Paradoxes. Strategic Depth through Soft Power: The Domestic Production and International Projection of Turkish Culture, 16.

18. Cerami C (2013) Rethinking Turkey's Soft Power in the Arab World: Islam Secularism, and Democracy. Journal of Levantine Studies 3: 129-150. 